IZA DP No. 9234

Immigration and School Choices in the Midst of the Great Recession

Lídia Farré

Francesc Ortega

Ryuichi Tanaka

July 2015 


\title{
Immigration and School Choices in the Midst of the Great Recession
}

\author{
Lídia Farré \\ University of Barcelona, IAE-CSIC \\ and IZA \\ Francesc Ortega \\ Queens College, CUNY \\ and IZA \\ Ryuichi Tanaka \\ University of Tokyo
}

Discussion Paper No. 9234

July 2015

IZA

P.O. Box 7240

53072 Bonn

Germany

Phone: +49-228-3894-0

Fax: +49-228-3894-180

E-mail: iza@iza.org

Any opinions expressed here are those of the author(s) and not those of IZA. Research published in this series may include views on policy, but the institute itself takes no institutional policy positions. The IZA research network is committed to the IZA Guiding Principles of Research Integrity.

The Institute for the Study of Labor (IZA) in Bonn is a local and virtual international research center and a place of communication between science, politics and business. IZA is an independent nonprofit organization supported by Deutsche Post Foundation. The center is associated with the University of Bonn and offers a stimulating research environment through its international network, workshops and conferences, data service, project support, research visits and doctoral program. IZA engages in (i) original and internationally competitive research in all fields of labor economics, (ii) development of policy concepts, and (iii) dissemination of research results and concepts to the interested public.

IZA Discussion Papers often represent preliminary work and are circulated to encourage discussion. Citation of such a paper should account for its provisional character. A revised version may be available directly from the author. 


\section{ABSTRACT \\ Immigration and School Choices in the Midst of the Great Recession*}

This paper empirically analyzes the effects of immigration on the schooling decisions of natives. We employ household-level data for Spain for years 2000-2012, a period characterized by a large immigration wave and a severe recession. Our estimates reveal that Spanish households responded to immigration by increasing their educational expenditures. This result was mainly driven by an important native flight from tuition-free schools toward private ones. We also find strong evidence of cream-skimming: only the more educated native households switched to private schools in response to immigration. Finally, our simulations suggest that the reduction in household income due to the Great Recession mitigated the flight toward private schools triggered by immigration but was not enough to offset it. We argue that these findings are driven by several factors: school assignment rules, concerns over negative peer effects, and political economy forces.

JEL Classification: D7, F22, H52, H75, J61, I22, I24

Keywords: education, public school, recession, immigration

Corresponding author:

Francesc Ortega

Department of Economics

Queens College, CUNY

300A Powdermaker Hall

65-30 Kissena Blvd.

Queens, New York 11367

USA

E-mail: fortega@qc.cuny.edu

\footnotetext{
* We are grateful for their comments to Martha Bailey, Caterina Calsamiglia, Julie Cullen, Christian Dustmann, Jesus Fernandez-Huertas, Rania Gihleb, Albrecht Glitz, Libertad Gonzalez, Joan Llull, Alkis Otto, Miquel Pellicer, Javier Polavieja, Sara de la Rica, Nuria Rodriguez-Planas, Thomas Siedler, Max Steinhardt, Steve Stillman, Chris Taber, Marcos Vera-Hernandez, and seminar participants at the Barcelona GSE Summer Forum, the 2014 ESPE conference, Hamburg University and the 2015 Eastern Economic Association.
} 


\section{Introduction}

Public education is a fundamental engine for human capital accumulation, with important consequences for income inequality and upward mobility. ${ }^{1}$ This is particularly so for first and second-generation immigrants, who disproportionately attend public schools and for whom socio-economic assimilation depends greatly on the quality of public education (Zimmermann et al. (2008), Dustmann et al. (2012)). In the aftermath of the Great Recession public education, and public expenditures more generally, have suffered severe budget cuts in many countries. This has been particularly the case for countries in the Euro zone that had to be bailed out due to large debt and severely restricted access to international borrowing, such as Greece, Ireland, Portugal or Spain.

The purpose of our paper is to estimate empirically the effects of immigration on the education system of the receiving country, with an emphasis on the consequences for the public-private school choice of natives. We employ data for Spain over the period 2000-2012, a country that over this period experienced a very large immigration wave and a very severe recession, and we use the Great Recession as a benchmark for assessing the magnitude of the effects of immigration. ${ }^{2}$

Our paper makes several important contributions. First, it contributes to the literature on the effects of immigration on the schooling choices of natives by our novel use of household expenditure data. ${ }^{3}$ Data on tuition expenditures allow us to go beyond the dichotomous public-private choice and analyze also the intensive margin of that decision. That is, we are able to identify moves from one private school to another with a different level of tuition. Second, these data also allow us to test for heterogeneous effects of immigration across households with different socio-economic status, which we refer to as the cream-skimming hypothesis (as in Altonji et al. (2010)). If confirmed by the data, this finding would have important policy implications since it would suggest increased segregation in schools, not just by nativity and ethnicity, but also by socio-economic status (Gould et al. (2009)).

\footnotetext{
${ }^{1}$ See, for instance, Glomm and Ravikumar (1992), Galor and Zeira (1993), Fernandez and Rogerson (1996) among many others.

${ }^{2}$ Throughout the paper we refer to the large immigration wave experienced by Spain between the late 1990 s and the late 2000s as the Great Immigration.

${ }^{3}$ In a recent study Dustmann et al. (2015) use expenditure data to analyze the effects of gaining legal status on consumption.

${ }^{4}$ This is a widespread problem in countries with high volumes of recent immigration. For instance, in Germany one in four immigrant children attend a school where immigrants are the majority group (Educational Reporting Consortium 2006). Moreover, these schools are often assessed to be underfunded and provide low quality education (Stiftung Mercator 2013). Not surprisingly, parents with higher education (native or immigrant) shun this schools.
} 
Finally, the empirical analysis that we propose also offers a test of the main predictions of the highly influential political-economy theory of education by Epple and Romano (1996).

We believe the recent Spanish experience is useful to analyze these questions. Between 1995 and 2007, Spain experienced a period of fast-paced economic growth. During this period the employment to population ratio increased by 14 percentage points (from 0.38 to 0.52 ). The economic boom fueled a spectacular immigration wave. Between years 2000 and 2008 the foreign-born share increased by about 10 percentage points (reaching $14 \%$ in year 2009), as illustrated by Figure $1 .^{5}$. Since the second half of 2007, the country has been immersed in a very severe recession. Between 2007 and 2012, the employment rate plummeted by almost 10 percentage points, real household income fell by over 13 percent, and the average number of individuals employed per household decreased by 17 percent, from 1.62 to 1.34 (Figure 2). ${ }^{6}$ Not surprisingly, in this context of deep economic recession net immigration has turned negative and the working-age foreign-born share has stabilized around 14 percent. The falling real wages and rising unemployment have severely reduced household income and expenditures, particularly for less educated households.

Clearly, immigration flows into Spain were strongly influenced by the economic cycle. Thus our empirical analysis needs to face an important challenge: the separate identification of the roles of income and immigration on the schooling choices of households. We do so by using household-level data combined with regional variation in immigration flows, and account for the classic endogeneity problem of the location choices of immigrants by adopting an instrumental-variables approach. ${ }^{7}$

Specifically, we estimate a series of household-level models where the main explanatory variables are household income and the foreign-born share in the household's region of residence. We provide both OLS and instrumental-variables estimates that exploit the roles of ethnic networks and migration costs in influencing the location choices of immigrants. In some of our models we also allow for heterogeneous effects of immigration across households with different education levels. We then use our preferred estimates to conduct counterfac-

\footnotetext{
${ }^{5}$ Like is several other European countries, large-scale immigration is a recent phenomenon in Spain, characterized by very high inflows over a short period of time with a high degree of heterogeneity. For a detailed survey on European immigration, see Zimmermann, ed (2005), Dustmann and Frattini (2011), or de la Rica et al. (2013)

${ }^{6}$ The economy slowly started to rebound in year 2013.

${ }^{7}$ Our specifications will control for household income thus there is a smaller scope for endogeneity bias than in studies of the wage effects of immigration. Our main interest is on the effects of immigration over school choices, rather than the well-known effect of household income. However, including household income in our empirical models allows us to compare the effects of immigration to those of the large household income shocks caused by the Great Recession.
} 
tual analysis. In particular, we compare the actual evolution of educational expenditures and school choice to what would have happened in the absence of the recession and in the absence of immigration. After presenting our reduced-form estimates we examine several possible interpretations for our results.

Our analysis delivers several interesting findings. First, we find that immigration led to an increase in tuition expenditures by Spanish households. This increase was fundamentally due to a native flight toward private schools, but not to upgrading within private schools. The magnitude of the effect was quantitatively very large. Immigration led to a 7 percentage-point increase in the share of households using private schools. In comparison the Great Recession and the subsequent austerity measures were responsible for only a 3-percentage point drop. Furthermore, we show that immigration led to increases in student-teacher ratios in public schools, which may have led to a deterioration in the quality of instruction, and that it triggered highly heterogeneous responses in the native population. Specifically, we find strong evidence of cream-skimming. Namely, it was primarily high socio-economic-status households that switched toward private schools, in line with the findings of Cascio and Lewis (2012) for the United States. In a similar vein, using data for Israel, Gould et al. (2004, 2009) show that high concentration of immigrant children in elementary schools may have negative long-term academic outcomes, both for native and immigrant students.

Our work is related to several strands of literature. Several authors have analyzed empirically the question of the effects of immigration for the schooling decisions of natives, and found evidence of a displacement of natives away from tuition-free public schools and toward private schools. Betts and Fairlie (2003) found that increases in the share of immigrants in a metropolitan area were associated to increases in the probability to attend private school among native households in California. ${ }^{8}$ Complementing the previous study, Cascio and Lewis (2012) found evidence of native migration to other school districts (within a metropolitan area) in response to inflows of Hispanic students with low English proficiency. ${ }^{9}$ Several authors have also found evidence of native displacement or immigrant segregation in schools in Europe. Kristen (2008) provides evidence for Germany, Gerdes (2010) for Denmark, and Schneeweis (2013) for Austria. In the light of these studies one would expect that Spain's large immigration wave should have led to a large shift away from public

\footnotetext{
${ }^{8}$ The finding appeared to be driven by responses to inflows of immigrant children who speak a language other than English at home.

${ }^{9}$ Saiz and Wachter (2011) study the effects of immigration on housing prices at the neighborhood level. In their paper they also document native flight toward other neighborhoods.
} 
school, and thus, to an increase in household spending in schooling.

Our paper is also related to the wider education literature on the role of parental education and socio-economic background as a determinant of children's outcomes. One reason for this is that more educated parents may be better informed regarding the options provided by the educational system and may also play a stronger emphasis on the education of their children. As a result, it is plausible that households with different education levels may respond differently to the same immigration shock. This heterogeneous response may have important welfare consequences, as in the analysis of cream-skimming in terms of school choices in Altonji et al. (2010). Naturally, the role of parental background is also a fundamental determinant of the educational outcomes of first and second-generation immigrants. In their comparative analysis of OECD countries, Dustmann et al. (2012) stress also the important role played by the quality of the schools attended by the children of immigrants. Furthermore, the education levels in one's neighborhood has also been shown to play a role (Chakraborty et al. (2014)).

Our work also complements the work by Hunt (2012) and Llull (2013) on the effects of immigration on the educational attainment of natives. While they focus on the consequences for native high-school completion rates and college attainment we focus on educational investments in compulsory education. Our use of education expenditures data follows the steps by Arellano and Zamarro (2007) who study school choice in Spain using data for 1990. Also Dustmann et al. (2015) have made use of consumption expenditure data on their analysis of the effects of legal status. Anghel and Cabrales (2010) study the roles of schools and parental background in standardized exams in Spain. Confirming previous studies, they find that parental background plays an important role. They also document important heterogeneity across children of different ethnic backgrounds, even after controlling for the parents' socio-economic status. However, they do not find evidence of a significant effect of class size or performance differences between public and 'concerted' (private but subsidized) schools, once parental background is controlled for.

Our work is also related to two recent studies that also rely on data for Spain. Ciccone and Garcia-Fontes (2014) make use of a rich dataset of students (from the region of Madrid) to propose a new approach to identify gender peer effects in schools. Calsamiglia et al. (2014) structurally estimate a model emphasizing the incentives faced by households in declaring their preferences over public schools as a function of the existing mechanism to match students to schools. More generally, our work is also related to a growing number of analyses of the effects of immigration in Spain, such as Amuedo-Dorantes and de la Rica 
(2007, 2011), Carrasco et al. (2008), Farre et al. (2011), Gonzalez and Ortega (2011), or Fernandez-Huertas et al. (2013).

The structure of the paper is as follows. Section 2 presents a concise description of the Spanish schooling system. Section 3 presents our empirical strategy. Section 4 describes our main data sources and provides summary statistics. Section 5 presents our estimation results. Section 6 presents counterfactuals to quantify the roles of the recession and the immigration wave on the schooling choices of households, and Section 9 concludes.

\section{Background}

\subsection{The Spanish Schooling System}

Since the early 2000s pre-university education in Spain can be described as follows. Compulsory schooling is composed of two stages: elementary (primary) school, consisting of six grades, and three years of secondary schooling (known as E.S.O, or Compulsory Secondary Schooling in its Spanish acronym). ${ }^{10}$ Students typically start compulsory schooling at age 6 and end at age 16. It is very common to begin school around age 3 : in the academic year 2010-2011 the enrollment rate for 3-year olds was over 96 percent. The main reason for this high rate is that preschool (ages 3 through 5) takes place at the same centers that offer elementary school and attending preschool guarantees a spot for elementary school. Thus, while voluntary, most families choose to begin schooling their children at age 3 . Accordingly, we will focus on tuition spending for households with children ages 3 through $17 . .^{11}$

Compulsory schooling in public schools is free of tuition and is fully financed by taxes. ${ }^{12}$ Besides private schools that do not receive government funding, the Spanish education system is characterized by the widespread use of publicly subsidized private schools, known as "concerted" schools, which account for about one third of all students. Concerted schools were introduced in 1985 to accommodate the increasing demand for education that resulted

\footnotetext{
${ }^{10}$ There was a gradual convergence to this system since the law was enacted (LOGSE) in 1990. By year 2000 it was almost fully implemented.

${ }^{11}$ While schooling is compulsory only up to age 16, we are forced to include also 17 year-olds because for the year 2000 to 2004 the household survey data does not differentiate between expenditure in compulsory and non-compulsory secondary education.

${ }^{12}$ Not surprisingly, public spending in education, as well as in other areas, fluctuates with the economic cycle. The share of public spending in education (including universities) over GDP increased from $4.27 \%$ in 2001 to $4.98 \%$ in 2009, and fell with the recession (4.74\% in 2011). Public spending in universities accounts for about $20 \%$ of total public spending in education. Public spending per student in primary education increased from 3,616 Euros to 5,169, a 42.9\% increase, between years 2003 and 2008 .
} 
from the baby boom and the increase in compulsory schooling age. ${ }^{13}$ In exchange for government funding that supposedly covers the school's whole salary bill, concerted schools agree to conduct an admission policy on the basis of the same criteria as public schools and to closely follow the core curriculum of public schools.

While, in theory concerted schools are not allowed to charge for tuition, in practice there are quasi-compulsory payments required from parents in terms of donations to the parents' association, building maintenance or financing of extracurricular activities. According to a 2012 study by the Association of Spanish Consumers (OCU (2012)), over 90\% of concerted schools require payments that are perceived by households as compulsory. These annual payments vary across Spanish regions, with regional averages ranging from 105 euros to about 1,000 euros. The average across Spain was 501 euros, with the highest values just shy of 2,000 euros. In comparison the analogous payments reported by public-school users were an average of 17 euros per year. Part of these expenses is incurred at the time of registration and the rest is paid monthly. The total disbursements collected from concerted school users tend to be much lower than the tuition charged by fully private schools.

A 2007 supplement to the Family Expenditures Survey reported average annual household expenditures per student disaggregated by type of school. Focusing on expenditures in tuition (upfront or as monthly fees) and extracurricular activities taking place within the schools, the average expenses per student in compulsory secondary school in public, concerted, and private schools were, respectively, 10 euros, 260 euros, and 2,223 euros. ${ }^{14}$ Hence, there are systematic differences in the tuition expenditures across public and private schools. As we will discuss in detail later, these differences in educational expenses will be important for our identification of public versus concerted schools in the data.

In practice there are important differences between public and concerted schools. First, in terms of student outcomes, Arellano and Zamarro (2007) report evidence that points to higher mean test scores for private schools, followed by concerted, and then public schools (Trillo del Pozo et al. (2006)). ${ }^{15}$ At any rate, the number of concerted schools between 1990 and 2010 has risen fast and immigration has been cited as one of the culprits (Llera and Perez (2012)). Second, the share of immigrant students in public schools is much higher

\footnotetext{
${ }^{13}$ The majority of concerted schools are Catholic. According to Arellano and Zamarro (2007) this is because one important goal of these schools was to provide affordable Catholic education.

${ }^{14}$ The corresponding figures for elementary school were 46 euros, 341 euros, and 1,765 euros.

${ }^{15}$ What is less clear is whether the source of the differences is due to sorting in ability and family background or to the value-added provided by the schools. For instance, Calero and Escardibul (2007) find that differences in performance between public and concerted schools are fully accounted for by family socio-economic characteristics. The findings by Anghel and Cabrales (2010) also point in this direction.
} 
than in concerted schools. In part this may be due to the larger out-of-pocket household expenses. $^{16}$

\section{$2.2 \quad$ Immigration and Schools}

Let us provide a few figures to illustrate the impact of immigration on the Spanish schooling system. Between year 2000 and 2010 the population of students with foreign nationality increased by a factor of 5.4, from 141,916 to over 770,384 students. ${ }^{17}$ The rise in this segment of the student population was very rapid until 2008 (when it reached 755,587 students) and has plateaued since then, reflecting the sharp reduction in immigration flows as the Great Recession hit the Spanish economy. Immigration is by far the main demographic factor behind the regional variation in enrollment levels in public schools, which can be seen in Figure 3.

The impact of immigration on public and private schools has been very uneven. In year 2000 the shares of foreign students in public and private schools were similar (2.3 and 1.4 percent, respectively). By 2008 the corresponding figures were 11.9 and 5.6 percent. ${ }^{18}$ That is, approximately a 10 percentage point increase in public schools compared to barely 4 in private schools. It is also worth pointing out that the immigrant population in Spain is very diverse in terms of origin. In 2010 the breakdown of the foreign student population by origin is as follows: $40 \%$ originated from South and Central America, 29\% from the rest of Europe, $23 \%$ from Africa, and about 6\% from Asia. Among all of these students, the vast majority are in public schools $(82 \%)$, with the remainder being distributed in $14 \%$ in concerted schools, and only $4 \%$ in fully private schools. In comparison, the breakdown for the overall student population, including native students, is approximately $68 \%, 27 \%$, and $5 \%$, respectively.

Methodologically, we rely on cross-regional variation to try to identify the causal effects of immigration on the school choices of households. Figure 3 suggests that this may be a particularly fruitful approach in the context of our application. It reports the percent change in the student population in each of the 17 regions (autonomous communities) in Spain. For the country as a whole the student population grew by about $10 \%$ during the

\footnotetext{
${ }^{16}$ It is also possible that the emphasis on Catholic education is an important deterrent for immigrant households with different religious backgrounds. de la Rica and Ortega (2009) report that 11 percent of the foreign-born population in Spain in year 2008 originated in Morocco. Adding also other immigrants from majority Muslim countries or followers of other religions leads to an important share of the immigrant population that may be disinclined to attend Catholic schools.

${ }^{17}$ These figures do not include students that have double nationality or second-generation immigrant children so it underestimates the impact of immigration on the schooling system in Spain.

${ }^{18}$ Source: Spanish Ministry of Education, Culture and Sports.
} 
decade of the 2000s. However, this masks a very large degree of regional variation. While some regions saw their student body shrink by about $15 \%$ (mostly regions in the North West of Spain), in some others it increased by about 20\% (mostly along the Mediterranean and Madrid). These wide regional disparities are fundamentally driven by differences in the size of immigration flows, relative to population, across regions (see Gonzalez and Ortega (2013) for more details). ${ }^{19}$ Thanks to our use of household-level data, we are able to identify the effect of household income in school choices on the basis of variation across households within a region in a given year.

\subsection{The Supply of Schools}

The number of students enrolled in the Spanish education system increased by 914,132 between years 2001 and 2011. Among these, 536,525 students were born abroad, and many others were born in Spain to parents that had recently immigrated. Just based on the foreign-born children, these figures show that the recent immigration wave was directly responsible for a 59 percent increase in student enrollment during the decade. Clearly, this calculation provides only a lower bound for the role of immigration in accounting for the overall number of students. ${ }^{20}$

To accommodate the net increase in the demand for education, the supply of schools and teachers was expanded importantly over the 2001-2011 period. According to the data, the numbers of public and private schools increased by 20 and 43 percent, respectively, and the numbers of teachers by 24 and 30 percent (Spanish Ministry of Education). ${ }^{21}$ Interestingly, these figures reveal a larger relative increase in the supply for education in the private system, even though enrollment increased relatively more in public schools. As a result, the student-teacher ratio increased more in public than in private schools. ${ }^{22}$

\footnotetext{
${ }^{19}$ Even though the teacher body expanded as well, by the end of the decade there were noticeable regional differences in the number of students per teacher across regions (Ministry Annual Reports and section 6.4).

${ }^{20}$ Taking into account the Spain-born children of recent immigrants, would lead to a more accurate picture. These figures refer to pre-university students (including elementary, primary and secondary compulsory and non-compulsory education).

${ }^{21}$ Specifically, the number of public schools increased by 3,052 and the number of private schools by 2,411 . In terms of teachers, the increases were 96,690 and 42,004 in public and private schools, respectively.

${ }^{22}$ In a later section we shall use regional variation on student-teacher ratios to assess the effects of immigration on school quality.
} 


\section{Empirical approach}

\subsection{Specifications}

Our micro data consists of annual cross-sections of household-level data and we restrict to households with school-age children. We adopt a reduced-form approach with the main goal of identifying the effects of immigration and household income as determinants of school choices. In our first empirical model the dependent variable is the log of education (mainly, tuition) expenditures per child for a household $i$ in region $r$ and year $t, e d u x .^{23}$ The righthand-side contains year and region fixed effects, a vector of household-level characteristics, the foreign-born share in the region $(F B S H)$, and a disturbance term. Specifically,

$$
\ln e d u x_{i, r, t}=\alpha_{t}+\lambda_{r}+\mathbf{X}_{i, r, t} \beta+\gamma F B S H_{r, t}+u_{i, r, t} .
$$

Importantly, vector $\mathbf{X}$ contains the log of real household income, together with educational attainment of the household head, household size, and the log of the regional GDP. The estimated coefficient for household income will be crucial in order to simulate the effects of the recession. We also note that by including year dummies we are taking into account Spain-wide trends in tuition spending. It is also important to note that the inclusion of regional dummies implies that the coefficient associated to the foreign-born share is identified from within-region variation over time. ${ }^{24}$ In comparison the identification of the coefficients associated to household-level variables, such as household income, is also aided by within-region-year variation across households.

We are interested in decomposing the effects of immigration on the intensive and extensive margins. In the context of our application, we want to distinguish between increases in tuition spending arising from a shift from tuition-free public school to a private school (extensive margin) from increases associated to a shift from one private school to another that charges a higher tuition (intensive margin). To isolate the intensive margin we estimate equation (1) on the subsample of households that use private school. In order to measure the extensive margin response we define a private school indicator, which takes the value of one if a household uses private school (concerted or not) for their children and zero otherwise. We then estimate a linear-probability model analogous to equation (1) but with the private-school indicator as dependent variable: ${ }^{25}$

\footnotetext{
${ }^{23}$ One euro has been added to the expenditure of all households to avoid taking the log of zero for households reporting zero tuition expenditures. All expenditure variables are at constant prices.

${ }^{24}$ We do not have household-level longitudinal data. Thus household-fixed effects cannot be included in the regression.

${ }^{25}$ We also report estimates of a probit version of this model.
} 


$$
\text { private }_{i, r, t}=\alpha_{t}+\lambda_{r}+\mathbf{X}_{i, r, t} \beta+\gamma F B S H_{r, t}+u_{i, r, t} .
$$

In addition to these specifications we also estimate extended versions of these models where we allow for a heterogeneous effect of immigration on the basis of households' education. Namely, we allow parameter $\gamma$ to vary by the education level of the household head.

\subsection{Estimation}

Initially we abstract from endogenity concerns and focus on examining the association between immigration and changes in school choices. By virtue of the regional dummies in (1), cross-regional variation in the size of the immigrant population over time is the basis for the identification of the effects of immigration on school decisions.

As in all empirical studies aimed at estimating the effects of immigration on the basis of spatial (cross-region) correlations, there is some concern that the least-squares estimates of $\gamma$ in equations (1) and (2) may suffer from endogeneity bias. Typically, in specifications that do not control for household income, one worries that individuals in regions experiencing positive income shocks will tend to increase spending in education (e.g. tuition or extracurricular activities), along with other spending categories. Since such regions are likely to attract more immigrants, one would expect an upward bias in this case. To take into account this potential endogeneity concern our empirical models include as additional control household income. However, it may also be that regions that experienced positive income shocks, both attracted more immigrants and, simultaneously, were able to increase the quality of public education. For example, they may have been able to reduce student-teacher ratios in public schools by hiring more teachers. The higher-quality public education would appear as a negative shock to tuition spending and private school attendance in equations (1) and (2). As a result, the OLS estimate of $\gamma$ is expected to be biased downward. ${ }^{26}$

Our IV strategy is rather standard and is based on building predictors of the regional foreign-born share that can be considered exogenous to unobserved region-level demand shocks for private schooling. We consider two instruments: a version of the ethnic networks instrument developed by Altonji and Card (1991) and Card (2001) and used extensively in the literature and the gateways instrument proposed by Gonzalez and Ortega (2013),

\footnotetext{
${ }^{26}$ Formally, the bias in the OLS estimate of $\gamma$ in equation (1) and (2) results from the omission of a relevant variable (i.e. public school quality) that is positively correlated with the foreign born share and has a negative impact on tuition spending and private school attendance.
} 
which is particularly appropriate for new immigration countries with few long-standing immigrant networks. We refer the reader to the appendix for more detailed definitions of these instruments. Throughout we report heteroskedasticity-robust standard errors that are clustered at the region level (17 clusters). ${ }^{27}$

It is worth noting that endogeneity concerns are less likely to be problematic in the context of our application than in the analysis of the labor market effects of immigration. The reason for this is that it is highly plausible that immigrants choose their region of residence on the basis of the current and expected state of the labor market. While this may correlate with education quality and tuition levels, the residual correlation (after controlling for regional aggregate income) between immigration flows and educational expenditures is likely to be less of problem. We will thus also test for the exogeneity of the foreign-born share regressor.

\section{Data}

Our main dataset is the Family Expenditures Survey (FES, or "Encuesta de Presupuestos Familiares" in Spanish), for years 2000-2012. ${ }^{28}$ The FES supplies detailed annual information on household consumption expenditures. The sample size is approximately 24,000 households per year and each household stays in the sample for two consecutive years. This survey is the main input in producing the private aggregate household consumption in the national accounts, and the consumption basket underlying the CPI calculations. In addition this survey is commonly used by social scientists to study many issues, ranging from housing and nutrition to healthcare and education (Arellano and Zamarro (2007) and Gonzalez (2013)). Several of the variables we employ in the analysis refer to the household head, defined as the main breadwinner (age 16 or older). If the person that contributes more to the household expenses is not a member of the household then the household head is considered to be the person in the household that receives the funds to finance most of the expenses.

Following Arellano and Zamarro (2007), we use tuition expenditures on compulsory schooling to identify school choices (public versus private). For our purposes it does not matter whether students attend a concerted or a fully private school. We view concerted schools simply as private schools with low tuition. Our key schooling expenditure variable

\footnotetext{
${ }^{27}$ For a detailed discussion of instrumental-variables estimation in a similar context, see Altonji et al. (2005).

${ }^{28}$ Prior to 2005 the survey was administered quarterly. Since 2006 it has become an annual survey. Except for year 2005 an annual dataset is available for the whole period 2000-2012.
} 
is normalized by the number of children in the household with age 3-17. On the basis of the questionnaire administered to the households, our educational expenditure variable contains annual tuition, registration, and related expenses, such as extracurricular activities offered within the school. These expenses may have been incurred once, typically at the beginning of the year, or periodically (e.g. in monthly installments). ${ }^{29}$

We define a household as a private school user if tuition expenditures are above 30 euros, measured at year-2011 constant prices. ${ }^{30}$ Arellano and Zamarro (2007) report that almost $80 \%$ of households with school-age children used public schools in year 1990. The average tuition paid by private users was 148 euros in 1990 (290 euros in 2011 prices) while it was zero for public school users (except for less than $0.2 \%$ of the sample, which were discarded). We note that their data was more disaggregated than ours, reporting separately tuition, extracurricular activities, school equipment, and so on. In light of their figures our choice of the 30-euro threshold is thus reasonable. As shown in Table 1, this threshold implies a share of households using private schools that ranges between 26 and $32 \%$ between 2000 and 2012 , that is, $68-74 \%$ of all households with school-age children relied on public schools. Compared to aggregate enrollment data, about $68 \%$ of students attended public school in academic year 2010-2011 (Ministry of Education, 2011). ${ }^{31}$ Since there is some misreporting in the tuition expenses we will conduct robustness checks where we define attendance to private school on the basis of a 100-euro tuition threshold.

The other key regressor in our analysis is the foreign-born share at the regional level (autonomous communities), which we build using the Continuous Population Registry, years 2000-2012. The evolution of this variable for the national aggregate is presented in Figure 1. In year 2000 the foreign-born share in Spain was 4 percent. It increased at a rapid pace until year 2009 when it reached 14 percent. Between 2009 and 2012 its rate of growth slowed down to almost zero. In addition, to build the ethnic networks instrument we also use the 1991 Population Census. The gateways instrument employs data from the 2007 National Immigrant Survey as well as a variety of other sources listed in the Appendix.

Our main sample are households with children aged 3 to 17 . Due to data limitations our

\footnotetext{
${ }^{29}$ School lunches and extracurricular activities that take place outside the school grounds are not included in this variable.

${ }^{30}$ We add one euro to all households annual income and tuition expenditure so that the log of these variables can be defined. Given our definitions of private school use this one euro addition will not have any effects on the results.

${ }^{31}$ Nationally this figure has been fairly constant for several decades: $66 \%$ in $1990,68 \%$ in 2000 and again in 2010. Of course this may be masking possibly significant changes at the regional level. For example, the share of elementary-school students in public schools in Catalonia (a region that has experienced high immigration) increased from 56\% in 1997 to $65 \%$ in 2009 .
} 
main sample includes both households headed by Spanish nationals and households headed by foreigners. For the 2000-2004 waves the FES does not report nationality or country of birth. Hence, for those years we are unable to distinguish between native and immigrant households. In part this reflects the fact that the share of households that were headed by immigrants was a relatively low share of the population at that time. As an important robustness check we also present estimates based on the sub-sample of Spanish households (for the period 2006-2012). At any rate we suspect that recent immigration may have affected Spanish nationals and earlier immigrants in similar ways.

Let us provide now some descriptive statistics. Table 1 reports the summary statistics of the sample (top panel) along with the population-weighted means for the key variables for selected years. After conditioning on having school-age children (ages 3 through 17) our sample consists of 59,809 households for the pooled years 2000-2012. The average number of kids in the sample is 1.48 . About $28 \%$ of the household heads are high-school graduates and $21 \%$ are college-graduates. On average the foreign-born share was 11 percent, across regions and years. About 41 percent of the immigrant population originated from other European countries and 38 percent from (Central and South) America. According to our main definition of private school user (30 euro tuition threshold) the share of households using private school is $33 \%$, which falls to $24 \%$ when we use the more stringent 100 euro tuition threshold. Annual household income is on average slightly above 25,000 euros, and for the years with existing data, the average income among households with an immigrant head was about 82 percent of the corresponding value for native households. ${ }^{32}$ The average real tuition is 265 euros. However, the vast majority of households report zero tuition (public school users). Approximately $67 \%$ of the sample spent less than 10 euros on tuition, despite having school-age children. About 8\% spent between 10 and 100 euros, 21\% spent between 100 and 2000 euros, and 3.6\% of the sample spent over 2,000 euros in tuition. Conditioning on private school use the average tuition rises to 865 euros.

Table 2 reports population-weighted means at 4-year intervals for the key variables. Several interesting trends stand out. First, there is a sustained reduction in family size in terms of the number of school-age children and a substantial increase in the foreign-born share, from 1.51 in year 2000 to 1.45 in 2012. There is also substantial skill upgrading, with the share of high-school graduates and college graduates increasing by 14 and 4 percentage points, respectively, throughout the period (Figure 4). The foreign-born share increased

\footnotetext{
${ }^{32}$ Real household income is a bit higher than nominal household income because we are reporting year-2011 constant prices. Hence, earlier years need to be inflated.
} 
by 9 percentage points between years 2000 and 2008, reaching 13 percent in 2008 (and 14 percent in 2012). During this period the largest immigrant groups were Europeans and Americans, followed by Africans. Throughout the decade the table reveals an important increase in the share of Americans, at the expense of declining shares of European and African immigrants.

The table also shows that the share of households using private school increased moderately, from $26 \%$ to $32 \%$. As a result, we observe an increase in average real tuition from 229 to 311 euros (in constant 2011 prices). Tuition also increased for private schools, starting at 866 euros in year 2000, peaking at 1,049 euros in 2008, and falling slightly to 1,037 euros in 2012. Figure 5 and Figure 6 report the trends for real tuition expenditure and the private share by education level of the household head. Naturally, more educated households spend uniformly more and have higher private shares than less educated ones. The only noticeable difference over time is an increase in the private share and in tuition expenditure for households headed by a college graduate from year 2004 onward.

It is also interesting to compare the characteristics of households using private and public schools. Table 3 provides the means for a number of variables conditional on school choice for years 2000 and 2010. As expected, in year 2000 private users are characterized by higher household income (34\%) and higher educational attainment, with the share of college graduates among household heads at 33\%, compared to only $15 \%$ among public school users. Practically the same gaps in income and educational attainment can also be seen in the data for year 2010.

\section{Estimates}

We begin by estimating our household-level models for tuition expenditures and school choices. At the end of the section we turn to region-level models for student-teacher ratios.

\subsection{Baseline Model}

\subsubsection{OLS estimates}

Let us begin by examining the OLS estimates for log real tuition expenditures. We also conduct a decomposition of the adjustments along the intensive and extensive margins. The former refers to changes in tuition spending for the sample of households using private schools. The extensive margin refers to the specification where the dependent variable is an indicator for using private school. 
Table 4 reports the OLS estimates. Column 1 fits a linear regression model for the log of real tuition on all regressors except for the FBSH. As expected, we find that household income and the education level of the household head are positively associated with tuition expenditure. Specifically, a one percent increase in household income is associated to a 0.5 percent increase in tuition expenditure. ${ }^{33}$ In contrast, households with a larger number of children tend to use schools with lower tuition. All specifications control for regional GDP (in constant prices) in order to control for regional tax revenue, which may also affect the quality of public education, and to better identify the effect of the foreign-born share at the regional level. Nevertheless this variable is almost never significant. Column 2 reports the OLS estimates of the model in equation (1). The point estimate of the FBSH is positive (4.71) and highly significant and the coefficients associated to all other regressors are practically the same as in column 1 . This makes sense because all of these variables (except for the regional GDP) are identified off of individual variation within a given region and year, unlike the FBSH which is identified off of within-region variation over time.

Columns 3 and 4 estimate the same model on two non-overlapping sub-periods. The estimates obtained using data for the pre-recession years (column 3) are very similar to those presented in column 2. Interestingly, even though the number of observations is much smaller in column 3, the standard error associated to the FBSH is substantially smaller than in column 2. In column 4 we use the sample covering the years of the Great Recession, 2008-2012. Now the coefficient on the FBSH is not statistically significant. The reason for this reversal is that the foreign-born share has been calculated using administrative data (the population registry). While these data have the advantage of referring to the whole population, and not just a sample, year-to-year changes in the registry may be inaccurate in periods of net outmigration, such as the Great Recession. ${ }^{34}$ In Spain individuals settling in a region (both native and foreign-born) have a large incentive to register with the local authorities in order to gain access to public healthcare and education. However, when individuals leave a city to go abroad they may not communicate this to the municipality and it takes some time until the local registry accurately reflects this change. Thus the prerecession years provide a safer basis for identification of the effect of the regional foreign-born share. At any rate we provide an important robustness check in Table 10 by estimating our model using long (5-year) differences, which should not be affected by this short-term

\footnotetext{
${ }^{33}$ Escardibul and Villarroya (2005) use data from the PISA study and find that high socio-economic status significantly increases the probability of attending private and concerted schools in Spain.

${ }^{34}$ This has been discussed in Gonzalez and Ortega (2013) and also in de la Rica et al. (2013) in the context of administrative data for other countries.
} 
measurement error.

Columns 5 and 6 investigate to what extent the positive effect of immigration on tuition expenses is due to a switch toward more expensive private schools by households that were already private-school users (intensive margin of adjustment), or to a switch from tuitionfree public schools toward private schools (extensive margin). In column 5 the sample is restricted to households that use private schools. In this case the point estimate associated to the FBSH is positive but not statistically significant, suggesting at most a small role for adjustments along the intensive margin. It is worth noting that the point estimate on household income remains positive and highly significant, implying that there will be adjustments along the intensive margin in response to shocks to household income such as a recession. Column 6 estimates a linear probability model where the dependent variable is an indicator for attending private school. Now we do observe a positive and highly significant positive coefficient (0.67). On the basis of this estimate, a 10 percentage-point increase in the share of foreign-born in a region is associated to a 6.7 percentage-point increase in the probability to attend private school. Not surprisingly, household income and higher educational attainment are also associated to a higher probability of using private schools. Column 7 presents the marginal effects of a probit model for the probability to attend private school, which are almost identical to the estimates of the linear probability model. In column 8 we provide sensitivity analysis to the estimated extensive margin effect by considering a different tuition threshold to assess attendance to a private school (100 euros). ${ }^{35}$ The results are again very similar to those reported in columns 6 and 7 . On the basis of the OLS estimates, our intensive-extensive margin decomposition suggests that immigration may have induced switching to private schools, but not upgrading within the private school sector. Of course, at this stage this is just an association and we are not making any causal statements.

\subsubsection{Two-stage Least-square estimates}

Of course OLS estimates may suffer from endogeneity bias, although the concern here is somewhat smaller than in wage regressions, as discussed earlier because educational expenditures for compulsory schooling in Spain are very low, accounting for a very small share of household expenditure in the vast majority of cases. Regardless of the direction of the bias it seems sensible to rely on instrumental-variables estimation in order to provide

\footnotetext{
${ }^{35}$ Recall that we do not directly observe if a household is using private or public school. Instead we infer this on the basis of the expenditure on tuition. Public schools are free of tuition but we consider positive (though small) tuition expenditure thresholds to account for misreporting and measurement error.
} 
more robust estimates of our coefficients of interest. Additionally, we can also control for aggregate regional income directly in the regression, which should help mitigate these biases.

Table 5 provides our two-stage least-squares (2SLS) estimates. In column 1 the dependent variable is the total tuition expenditure per child (at constant prices) for all years in our sample. The main observation is that the point estimate on the FBSH is positive and highly significant. The magnitude implies that a 10 percentage-point increase in the FBSH leads to more than doubling tuition expenditures. ${ }^{36}$ As expected, we also find that household income plays an important role, with a tuition-income elasticity of about 0.5 , and that more educated households send their children to schools that charge higher tuition. Finally, households with more children make use of schools with lower tuition. Regional GDP does not seem to play an effect on households' school choice and the resulting tuition expenditure. Qualitatively, these results confirm those that emerged from the OLS estimates.

Columns 2 and 3 report estimates for the same model but for different sub-periods. While the results are qualitatively similar, we note that the coefficient on the FBSH increases as we include more recent years, ranging from 8.32 for the years 2000-2007 to 13.11 for years 2000-2012. In addition as we expand the number of years the goodness of fit and the precision of the estimate for the FBSH fall. What is going on? One hypothesis, which we confirm in the next section, is that there is a composition effect. Different groups of natives have different responses to immigration and over time the group displaying the largest response to immigration has become more prevalent. In addition, as was the case in Table 4, the standard errors are lower for the smaller sample than for the larger ones. For our preferred sample (pre-recession years 2000-2007) the IV estimate for the FBSH is 8.32, substantially larger than the OLS estimate on the same sample (4.58) but also estimated much more imprecisely.

Columns 4-6 investigate to what extent the previous positive effect of immigration on tuition expenses is due to a switch toward more expensive private schools by households that were already private-school users (intensive margin). The point estimates for the FBSH are not significantly different from zero, suggesting that immigration does not lead to school upgrading among private school users. In contrast household income remains highly significant and thus a recession that lowers household income will induce reductions in tuition expenditure for households using private schools. Columns 7-9 examine the extensive

\footnotetext{
${ }^{36}$ Suppose that the FBSH increased by 0.10 between periods 0 and 1 . Simple manipulation shows that the increase in real tuition is given by edux $1 / e d u x 0=e^{\beta \times 0.10}$.
} 
margin of adjustment, that is, to what extent the increases in tuition documented in columns 1-3 are due to switching from tuition-free public schools toward private schools. Across the three columns we find positive and significant effects of immigration and household income. Again there appears to be an upward trend in this coefficient, ranging from 1.31 when we only use years 2000-2007 to 1.95 when we use the whole period 2000-2012. As was the case for overall tuition expenditures, both the IV point estimate and its associated standard error are noticeably larger than the corresponding OLS values.

In a nutshell, the 2SLS estimates largely confirm the OLS results: increases in the regional foreign-born share are associated to increases in tuition expenditure. In addition this effect seems to be driven by adjustments along the extensive margin, that is, families switching from tuition-free public schools toward private ones. The 2SLS estimates of the coefficient of the FBSH are higher than the corresponding OLS estimates, although also much less precisely estimated. This downward bias in OLS is consistent with the view that immigrants disproportionately flock to regions with a positive, unobserved shock to the quality of their public schools, perhaps reflecting a positive, unobserved shock in aggregate income and tax revenue. These shocks lead to reductions in households out-of-pocket tuition expenditures because many households find it worthwhile to send their children to tuitionfree public schools.

Let us now discuss further the quantitative implications of our estimates. In particular, should we base our counterfactual analysis on the smaller OLS elasticity or the larger but less precise 2SLS estimate? To address this question we perform a test of endogeneity. Specifically, we wish to test the null hypothesis that the regional foreign-born share (FBSH) is an exogenous regressor. Under the null the OLS estimates are both consistent and more efficient than 2SLS. The last row of Table 5 reports the p-values of the Durbin-Wu-Hausman test (robust to clusters and heteroskedasticity) for our main specification across several samples (columns 1-3). In column 1 we include all years between 2000 and 2012. In this case we are able to reject the null of exogeneity for FBSH (p-value 0.03). But, as argued earlier, our preferred sub-sample is for years 2000-2007 (column 3). In this case we are not able to reject the null of exogeneity ( $\mathrm{p}$-value 0.23 ). On the basis of this test we shall conduct our counterfactual analysis in Section 6 relying on the more precise OLS estimates.

\section{Counterfactuals}

In this section we try to disentangle the effect of the Great Recession from that of the immigration wave and to convey the magnitude of the effects of each of these shocks on 
school choices. We do so by simulating a number of counterfactual scenarios. Our counterfactual exercises are constructed as follows. Using our preferred sets of estimates, ${ }^{37}$ we produce household-level fitted values under actual data and under counterfactual datasets that depict our scenarios of interest. ${ }^{38}$ Then we aggregate across households in each year and plot average responses in our figures.

\subsection{What if the Great Recession had never happened?}

We begin by the more straightforward analysis of the effects of the recession, which provides a useful benchmark. Intuitively, as earnings fell during the recession households must have been forced to cut on all sorts of expenditures, including educational expenditures as well as other items in the household budget. The previous estimates revealed a positive income elasticity (about 0.6). Hence, on the basis of the previous estimates a 10 percent drop in household income would be associated to a reduction in tuition spending of about 6 percent and a resulting drop in the share of households using private schools.

On the basis of our estimates, we conduct the following counterfactual experiment. For each region we compute the average household income in year 2007 by education level of the household head. We then build a counterfactual dataset where for all years between 2008 and 2012 each household is assigned the constant average household income in its region-education cell in year 2007. ${ }^{39}$ We then aggregate individual predictions year by year. It is worth noting that the model includes year dummies. Hence, it can match perfectly the average tuition year by year.

The results are plotted in Figure 8. This figure reports average real tuition expenditure (in log points). As seen in the (blue) solid line, the actual data (and the fitted values) show a sustained increase between 2003 and 2007. During the Great Recession (2008-2012) real average tuition expenditure was practically constant. The (red) dashed line reports the counterfactual evolution of real average tuition spending per child. In the absence of the recession real tuition expenditure would have increased sharply, roughly at the same

\footnotetext{
${ }^{37}$ On the basis of the endogeneity tests reported in Table 5 and Table 7 we focus our quantitative analysis on the more precise OLS estimates. We estimate these models on the sample that includes all years so that we obtain estimated year effects for every year between 2000 and 2012. Specifically, in the regression for the log of educational expenditures, the point estimates (and associated t-statistics) for $F B S H, F B S H \times G r a d u a t e$, and the log of real household income are $1.62(0.76), 5.75$ (1.88), and 0.83 (6.79). Similarly, in the regression for attending private school the estimated coefficients are $0.01(0.05), 0.86$ (2.16), and 0.12 (7.44).

${ }^{38}$ In building the predictions we use all estimated coefficients, regardless of whether they are significant at conventional levels.

${ }^{39}$ Note that we are allowing the recession to hit households asymmetrically depending on their education level. We also assume that real GDP remained constant at its 2007 level.
} 
rate as in the 2003-2007 period. Based on our findings between 2007 and 2012 real tuition expenditures would have increased by about 30 percent in the absence of the recession. Instead they remained essentially flat. A simple measure of the accumulated effect of the recession is the comparison between the actual year-2012 tuition expenditures and the counterfactual expenditure in that same year. Our simulation implies that average tuition expenditure would have been 27 percent higher in year 2012 in the absence of the recession.

Let us now turn to the consequences for the public-private school choice (extensive margin), which provides a more straight-forward measure of the effects of immigration. Figure 9 plots the probability of using private school. As in the previous figure we note an upward trend in the data between years 2003 and 2007 that was halted by the Great Recession. In the absence of the recession private school attendance would have continued rising. According to our simulation between years 2007 and 2012 the share of households using private schools would have increased by about 3.8 percentage points in the absence of the recession. Turning now to the comparison of 2012 values in the actual data and in the counterfactual, we find that without the recession the share of households using private schools in year 2012 would have been 3.3 percentage points higher than we observe in the data. ${ }^{40}$ Taken together these findings reveal a large impact of the Great Recession on the educational investments of Spanish households, with the adjustment taking place primarily in the choice between public and private schools.

\subsection{What if the Great Immigration had not happened?}

As we have learned from our estimates, increases in the foreign-born share are associated with higher tuition expenditure and higher private school attendance. Hence, in the absence of immigration a higher share of students would have attended public schools. Thus, in a way, the immigration wave and the Great Recession affected households' schooling decisions in opposite directions. It is therefore interesting to compare the magnitudes of the effects of both shocks.

We simulate the effects of the immigration wave on the basis of the same estimates as in the previous counterfactual. Specifically, we compute predicted values for a counterfactual scenario in which each region's foreign-born share remained constant at its 2000 level. ${ }^{41}$ The results are plotted in Figure 10 and Figure 11. In both figures the (blue) solid line is

\footnotetext{
${ }^{40}$ Although we do not report this figure, we also evaluated the intensive margin effect. The simulation shows that year 2012 average tuition spending among private school users would have been about 5 percent higher in the absence of the recession. However, we note that this result is based on non-significant estimated coefficients.

${ }^{41}$ For the average individual this implies a regional foreign-born share of 4 percent.
} 
the actual data. As we discussed earlier, the data show rising average tuition expenditures (in real terms) for the period 2003-2007, followed by almost stagnation during the Great Recession. The bottom figure exhibits a very similar profile: the private share increased from about 0.25 in 2003 to 0.32 in 2007, remaining roughly flat over the next five years.

Let us now turn to the (red) dashed lines in the figures, which depict the counterfactual real tuition expenditure and private share under the no-immigration scenario. Thus the comparison between the actual data (blue solid line) and the no-migration scenario (red dashed line) identifies the effects of immigration. Clearly, in the absence of immigration both real tuition expenditures and the private share would have been substantially lower. Between 2000 and 2012 real expenditures would have fallen by 27 percent while the share of households using private schools would have fallen by almost 2 percentage points.

We also plot in Figure 10 and Figure 11 the results for a third counterfactual scenario where the foreign-born share in each region would have remained at the level of year 2000 and average household incomes (by education level) would have remained constant between 2007 and 2012. This is the no-immigration and no-recession scenario (green long-dash line). Thus the gap between the (red) dashed and the (green) long-dashed lines identifies the effects of the recession.

Let us focus first on tuition expenditures. As we have just discussed, average tuition expenditures in 2012 would have been much lower in the absence of immigration. In contrast, the recession pushed in the opposite direction. Consider, for instance, year 2012. The implied causal effect of immigration, estimated by comparing the 2012 values across scenarios, is an increase in expenditure of about 40 percent ( $0.50 \log$ points). In comparison the causal effect of the recession is about half as large ( 0.25 log points). We now turn to the probability that a household chooses private school for their children, our preferred measure of the effects of immigration. The results show that the private share in 2012 would have been much lower in the absence of immigration. As illustrated in the figure the 2012 private share would have been 0.25 , about 7 percentage points lower than the observed value for that year (0.32). In comparison the effect of the recession amounted to slightly more than 3 percentage points.

From a quantitative standpoint our findings reveal that the Great Immigration has had very large effects on the school choices of Spanish households. By our measures its effect has been about twice as large (in absolute value) as that of the Great Recession. 


\section{The Mechanisms}

The previous section has established that increases in the foreign-born population in a region lead (native) households to shift from public to private schools. We now wish to examine the mechanisms behind this displacement effect.

\subsection{School assignment rules}

In Spain, as well as in many other countries, households submit school preferences and local governments match students to public schools on the basis of some pre-specified assignment rule. $^{42}$

Specifically, most Spanish cities follow the so-called Boston Mechanism. Households submit applications where they rank schools according to their preferences. ${ }^{43}$ Whenever possible, children are allocated to their first choice. Naturally, some schools are oversubscribed because they are viewed as more desirable due to their location, teacher quality, peer effects, and so on. In these cases, applications are ranked using some priority rules, which award points on the basis of family characteristics. ${ }^{44}$ The school is then filled with the applicants with the highest priority. After having matched students to schools on the basis of their first choice in this fashion, the remaining students are then allocated to the schools that still have vacancies.

Importantly, priority rules typically award points to households with lower income and larger family size. As a result, on average, applications from immigrant households tend to obtain higher scores, displacing native households to schools with lower demand. Since private concerted schools require payments, they are viewed as relatively less desirable than public schools, which are free. ${ }^{45}$ Thus an inflow of immigrants with lower average income than natives will mechanically induce an increase in tuition expenditures by native households, as they switch toward (concerted) private schools. Of course, it is also possible that natives are displaced from more to less preferred public schools. ${ }^{46}$

\footnotetext{
${ }^{42}$ Private schools are free to set their own admissions criteria.

${ }^{43}$ Seats in both public and concerted schools are assigned in this way.

${ }^{44}$ For example, in the case of Barcelona, having a sibling already in the school awards 40 points, living in the schools catchment area awards 30 points, and families from disadvantaged economic backgrounds have 10 additional points. See Calsamiglia and Guell (2014) for a detailed description of the allocation rules.

${ }^{45}$ In theory private concerted schools are tuition free. But this is far from the reality. Virtually all private concerted schools ask for payments, which are viewed as compulsory by parents (OCU (2012)), as discussed in Section 2.1. In addition concerted schools are typically Catholic and a large fraction of the immigrant population is not.

${ }^{46}$ In Section 2.3 we provided a description of the expansion in the number of schools and teachers over our period of interest. The data shows that the supply of seats was enough to absorb the demand. However, the point here is that the sorting between students and schools may have been affected.
} 
It is also important to recognize that this explanation is only satisfactory in the short run since it takes the quantity and quality of schools as given. Over time voters can decide to change the level of funding or create new schools. Or can also respond to an increasing concentration of immigrant children in a school by switching to other schools for reasons other than school funding and quality.

\section{$7.2 \quad$ Peer effects}

An alternative view maintains that schools are similar in terms of desirability in the eyes of native households. However, parents may be biased against schools with a high density of immigrant children due to concerns about a negative peer effect on the educational outcomes of their children. This could arise if teachers are overburdened due to a lack of language fluency of immigrant children, if immigrant children come from more disadvantaged families, or if natives perceive that immigrant parents do not care as much as they do about the education of their children, among other reasons. ${ }^{47}$

Since the immigrant population is a highly heterogeneous population, e.g. in terms of Spanish language fluency, we would expect differences in the effects of immigration according to the mix of immigrants received by each Spanish region. To try to test this explanation we extend our empirical model by disaggregating the foreign-born population into several groups according to their origin. If we find that native households respond differentially to inflows of immigrants of one origin or another we may get important clues regarding the reasons for this differential response. ${ }^{48}$

Specifically, we build a series of variables that capture the composition of the immigrant population by region (continent) of origin. ${ }^{49}$ Table 1 presents some summary statistics. Across all years and regions of Spain the average foreign-born share was 0.11. Among the immigrant population, European immigrants accounted for 41 percent, African immigrants for 17 percent, immigrants from the American continent for 38 percent, and immigrants from Asia and Oceania for 4 percent. $^{50}$ Table 2 provides the evolution of the immigrant

\footnotetext{
${ }^{47}$ It is also possible that differential response simply reflects that native households dislike some immigrant groups more than others, due to religious or racial prejudice.

${ }^{48}$ Unfortunately, we do not have information in the Population Registry on the socio-economic status of the immigrant population, only their age, gender, and country of birth. Thus we focus on average effects by immigrant origin.

${ }^{49}$ Breaking up the immigrant population by country of birth was not feasible. A reasonable compromise was to partition immigrants by continent of origin.

${ }^{50}$ Naturally, some groups of immigrants were more heavily concentrated in some regions than in others. However, since our partition of immigrants by region of origin is rather coarse, at the level of continents, all regions contain at least some immigrants from each group for all years. As documented in detail in de la Rica and Ortega (2009), a handful of countries account for most immigrants. As of 2012, the main source
} 
population, in size and composition, over the period 2000-2012. The immigrant composition has remained fairly stable over these years, with European and American immigrants topping the ranking. However, the table does show a clear reduction in the weight of European and African immigrants, from 68 percent of all immigrants in year 2000 to 58 percent in 2012. Practically all of this gain has gone to American immigrants, with the Asian share remaining almost unchanged over the period.

We now turn to our estimates, collected in Table $6 .{ }^{51}$ The first column reproduces our baseline finding, with a significant coefficient of 4.58 accompanying the FBSH. Next, we split the foreign-born share into 4 components: the shares of European, African, American and Asian immigrants over the whole population. ${ }^{52}$ In column 2 only the coefficient for the share of American immigrants in the population is significantly different from zero. However, this is driven by the fact that this group accounts for the lion's share of Spain's immigration wave. For this reason we turn to a specification that includes the overall FBSH in addition to three variables that measure the composition of the immigrant population in each region, namely, the number of immigrants from each continent as a share of the overall immigrant population. ${ }^{53}$ Columns $3-5$ present the results. In column 3 the dependent variable is the log of tuition expenditures. As before, the overall foreign-born share remains highly significant, with practically the same coefficient as in the baseline regression model. However, the variables summarizing the composition of the immigrant population are not statistically significant. The following two columns present our extensive-intensive margin decomposition. The dependent variable in column 4 is the indicator for the use of private schools. As expected, the overall foreign-born share is highly significant, with a coefficient in line with our previous results. We also obtain marginally significant results (at a 10 percent significance level) for some of the composition variables. Specifically, it seems that in regions with a predominance of (Central and South) American immigrants (holding constant the overall foreign-born share in the region), Spanish households are more likely to turn to private schools. ${ }^{54}$ On the contrary, a predominance of Asians in the immigrant population appears associated with a lower probability of turning to private schools. While weak in terms of statistical significance, these results are in line with the analysis in Tanaka et al.

countries are Morocco (Africa), Romania (for Europe), Ecuador and Colombia (for America), and China and Pakistan (for Asia and Oceania).

${ }^{51}$ The estimation sample is 2000-2007, which excludes the Great Recession. As discussed earlier, during these years the administrative data used to measured the immigrant population is very noisy.

${ }^{52}$ Naturally, these four components add up to the foreign-born share for each region and year.

${ }^{53}$ The omitted category is the share of European immigrants in the foreign-born population.

${ }^{54}$ The point estimate for the share of Africans in the foreign-born population is also positive but not statistically different from zero. 
(2014). In that study we calibrated a political-economy school-choice model to Spanish data and found that Asian immigrants are the group that produces the smaller degree of displacement of natives toward private schools. In the context of that model this finding is driven by the higher revealed preference for education of Asian immigrants in Spain. In conclusion we find some evidence, though far from conclusive, suggesting that the native flight that we have documented may be partly driven by cultural aspects. ${ }^{55}$

\subsection{Political economy}

The mechanisms above take as given the quality of public schools. However, one would expect that a large immigration shock may alter the political economy of public education, potentially affecting funding and quality. Crucially, voters' views will depend fundamentally on whether they choose to send their children to public or private schools.

In order to examine these issues it is helpful to build on the political-economy theory of education developed by Epple and Romano (1996) and extended by Coen-Pirani (2011) to analyze the effects of immigration. ${ }^{56}$ In this framework households are heterogeneous in (lifetime) income and on their taste for private education, and choose between public school (at zero tuition) and a menu of private schools that vary in tuition and quality. Each household has one school-age child and cares about the school quality (proxied by educational expenditure per student) and consumption of a numeraire good. Public education is financed by a proportional income tax, which is determined by majority vote.

For a given education policy, utility maximization implies that richer households opt out of public school and send their children to private schools. Conditional on income this is also the case for households with fewer children. Under reasonable assumptions on the utility function, the majority-vote equilibrium policy has the property of "ends against the middle": it balances the votes of middle income households against those of poor and wealthy households, the coalition supporting the lowest tax rate. More specifically, the richest households prefer a zero tax rate, which would imply the lowest level of quality for public education, because their children attend private schools. At the other end of the income distribution, low-income households prefer a low tax rate, even though they are public school users, because they cannot afford to pay higher taxes, which reduces their disposable income. Within this group, the individually preferred tax rate is increasing in

\footnotetext{
${ }^{55}$ One important caveat is that peer effects are likely to manifest themselves more clearly at the school level. Since our identifying variation is at the level of Spanish regions our test has only limited power.

${ }^{56}$ Another important contribution is citetFernandezRogerson:98 who focus on the public finance implications.
} 
household income. ${ }^{57}$

Next we describe the predictions of the model regarding our shock of interest: an immigration wave. We will then contrast these predictions with our empirical findings. Naturally, the effects of immigration depend crucially on the relative income of immigrants vis-a-vis natives. On average the income of immigrant households in Spain is only about 83 percent of the income of households with a Spanish household head. ${ }^{58}$ Hence, in terms of the model, we are interested in an inflow of households that reduces the average household income in the economy. ${ }^{59}$

Given the income tax rate, an immigrant inflow that lowers average household income will lead to lower tax revenue per household (and per student). As a result, educational expenditure per student in public schools is likely to fall, inducing some native households to opt out to private schools. Theoretically, public education expenditure per student could increase. However, this would only be the case if the number of incoming immigrant students into public school were smaller than the number of native students transferring out of public schools. This is unlikely since it requires an unrealistically large displacement effect. In their study for California Betts and Fairlie (2003) found that one native student switched to private school for every four new immigrant children in public schools. ${ }^{60}$ Cascio and Lewis (2012) report a similar magnitude for the effect of an increase in a district's (low-English) Hispanic share in public school enrollment on the private school enrollment of non-Hispanics. Our earlier finding of an increase in tuition expenditures (along the extensive margin) is consistent with the findings of these authors.

This native flight toward private schools reduces the political support for devoting resources to public education. As this happens, the public expenditure per student falls, triggering further native flight. ${ }^{61}$ Therefore, the model predicts that a low-income immi-

\footnotetext{
${ }^{57}$ For more details on the existence of such a majority-voting equilibrium and its properties, see Epple and Romano (1996) and Coen-Pirani (2011).

${ }^{58}$ These calculations are based on the Family Expenditures Survey for years 2006-2012 because for these years we have information on the nationality of the household head. We estimate that the average annual household income for native households is about 24,174 euros, compared to 20,065 euros for households with an immigrant household head, that is, 83 percent of the income of a native household. We also note that the native-immigrant income gaps vary by year, ranging from 0.95 at the peak of the boom (year 2007) to a low of 0.75 in years 2011 and 2012, and that the average wealth and home ownership rates are substantially lower among immigrant-headed households.

${ }^{59}$ We also assume that immigrants do not have the right to vote, which is the relevant case in our application. As argued in Tanaka et al. (2014) the displacement effects are larger when immigrants gain the right to vote. However, assimilation has the potential to mitigate these results.

${ }^{60}$ This displacement effect refers to high-school students. They did not find any displacement at the elementary school level.

${ }^{61}$ The intuition is similar to the one provided in Razin et al. (2002), who study the effects of immigration on income redistribution. They show that low-income immigration leads to less redistribution since the
} 
gration wave will entail (i) a reduction in the quality (expenditure per student) in public schools, and (ii) a displacement of native households toward private schools.

An additional prediction of the theoretical framework in Epple and Romano (1996) is that the natives that are displaced from public to private school by immigration are the wealthiest households among the public school users. Namely, immigration should have heterogeneous effects on native households. In our empirical model we control for current household income. But, unfortunately, we do not have information on households' assets in our dataset. We can, however, interpret the education level of household heads as a proxy for wealth or, perhaps more appropriately, expected lifetime income. From this viewpoint households with higher education will also tend to have higher wealth. Thus we expect iii) $a$ larger response by households with higher socio-economic status (as measured by educational attainment), or cream-skimming in the language of Altonji et al. (2010).

In the previous sections we have already documented an increase in tuition expenditures in response to immigration. This increase was fully driven by an extensive-margin response, that is, a native flight toward private schools. We next conduct tests of two additional predictions of the political-economy model: a larger response by households with high socio-economic status, and a deterioration in school quality.

\subsubsection{Cream-skimming}

Heterogeneous responses in terms of school choices have also been documented in the empirical literature. For instance, Altonji et al. (2010) document the cream-skimming effects of school choice. Their findings suggest that better students (in terms of ability or parental background) may be more responsive to change schools in response to changes in the environment such as the introduction of vouchers, or an important increase in the immigrant share in their region of residence.

We begin by examining the trends in the tuition expenditures data for each of the three education groups considered: low (high-school dropouts), medium (high-school graduates), and high (college graduates). As we saw in the earlier figures real tuition expenditure and the share of students in private in the aggregate have been increasing over the last decade. However, Figure 5 and Figure 6 reveal some important differences across education groups. We observe a clear increase in tuition paid and in the probability of attending private school among households with high socio-economic status (proxied by education), particularly

marginal cost of redistribution perceived by the median voter is now higher. They refer to this as the fiscal leakage effect. 
from 2004 onward. In contrast medium and low educated households have displayed fairly constant average tuition expenses. Overall these trends point to an increase in inequality in terms of households' educational investments. In order to test for heterogeneous effects of immigration on Spanish households we extend our empirical model in two ways. First, we include education-year dummy variables so that the model is able to account for the different national trends for each of the education groups. Second, we include interactions between education group dummies and the foreign-born share.

Table 7 presents the estimates of this augmented model. Columns 1-3 estimate the same model for tuition expenditures on 3 subsamples: 2000-2012, 2000-2010, and 2000-2007. The most remarkable observation is that now the coefficients on FBSH and its interactions with high-school graduate and college graduate indicators are fairly stable across the three columns. This provides evidence in support of the interpretation of a compositional effect in Table 5. Over these years the shares of medium and high educated households in the population were increasing, and these groups have higher responses to immigration. In fact, the estimates suggest that immigration had no effect on the schooling decisions of low-education households but did have a significant effect on the choices of households with higher socioeconomic status. In addition, in the extended model the standard errors associated to the coefficients for medium and high education are now decreasing in the number of observations, as one would expect. We note that the point estimate for the interaction term for college graduate households has relatively large standard errors reflecting the fact that this is a relatively small group. We also note that household income remains highly significant, with a tuition-income elasticity ranging between 0.50 and 0.66. As discussed earlier, our preferred subsample covers the pre-recession years, 2000-2007. In this period most regions were experiencing net immigration, which is accurately reflected in the population registry at an annual frequency.

In columns 4 and 5 we consider a more conservative specification where we restrict to two education levels: high-school dropouts versus high-school graduates and college graduates pooled together. ${ }^{62}$ As before, we find no evidence of a response by low-education households but a positive and significant effect for higher educated households. The two columns differ in the years used in the estimation. Column 4 uses all years available while column 5 uses only the pre-recession years. Naturally, we now obtain a more precise estimate for the effect of immigration on the highly skilled households than in the models with 3 education

\footnotetext{
${ }^{62}$ This partition splits the sample in half. In our data the shares of households with low, medium and high education are $51 \%, 28 \%$, and $21 \%$, respectively.
} 
classes. Our preferred specification is column 5 (pre-recession sample). In this specification the coefficient on the FBSH interacted with the indicator for high-school graduate (or higher attainment) is highly significant with a coefficient of 11.27. For this group the overall effect of a 10-percentage point increase in the share of foreign born on the log of tuition expenditures is 0.13 so approximately a 13 percent increase. ${ }^{63}$

Columns 6 and 7 present a decomposition of the effect in the previous column into extensive and intensive margins. In column 6 the sample contains only the households that use private school (intensive margin). Along the lines of our earlier results, we find no effect of immigration on low-education households. We find a marginally significant differential effect on households with higher education with a point estimate of 3.75 (and a p-value between 0.05 and 0.10 ). However, the overall effect for these households is not significantly different from zero. ${ }^{64}$ In other words we do not find evidence of an intensive-margin effect either for all households or for those with higher education. ${ }^{65}$ Turning now to the extensive margin (column 7) we find no response among low-educated households but a positive and significant effect on more educated households (with a coefficient equal to $0.59+1.46=2.05$ ). Column 8 provides a robustness check on the estimates of the previous column by employing a more stringent tuition cutoff to determine the use of private schools (100 instead of 30 euros). Reassuringly, the point estimates for the main coefficients are very similar in the two models.

Finally, columns 9 and 10 provide OLS estimates of the models in columns 5 and 7, respectively. Putting endogeneity concerns aside, these estimates are useful to evaluate if the partial correlations follow a similar pattern as the instrumental-variables estimates. This is indeed the case. In columns 9 and 10 the foreign-born share does not seem to have any effect on the schooling choices of low-educated households. However, we find a positive partial association between the regional foreign-born share and tuition spending and private school choice for households with at least a high-school degree. The OLS point estimates and the associated p-values are almost the same as for the 2SLS counterparts.

We also note that these findings are also consistent with Calsamiglia and Guell (2014).

\footnotetext{
${ }^{63}$ Namely, $(2.30+11.27) / 10$. For our preferred specification (column 5) we also conduct the test of endogeneity. Again we are not able to reject the null of exogenous regressors for the FBSH and its interaction with the indicator for having graduated from high school or college.

${ }^{64}$ The point estimate for households with at least a high school degree is $-4.09+3.75=-0.34$.

${ }^{65}$ It is possible that this finding may be due to the fact that we are controlling for household income. However, this is not the case. Even if we do not control for household income and the log of GDP we fail to find a response along the intensive margin. A possible interpretation is that private schools adjust their tuition rates to retain a fixed enrollment. If so they may react to an increase in demand due to a native flight out of public schools by increasing tuition up to the point that there is no net effect in enrollment.
} 
These authors provide evidence of strategic behavior in reporting school preferences to local governments. However, they also show that lower-education households tend to behave more naively. As a result, we may observe more switching among higher education households, which is what we have labelled cream skimming. In their view this heterogeneous response is not driven by differences in lifetime income, but rather in the ability to grasp the implications of the assignment mechanism.

Regardless of the specific mechanism behind the phenomenon of cream-skimming, the overall picture that emerges is one of increased inequality in educational investments as a result of immigration, with children of new immigrants and of low-education native households increasingly concentrated in public schools.

\subsubsection{Who are the switchers?}

We think it is interesting to try to learn more about the characteristics of the switchers, namely, the households that in the absence of immigration would have taken their children to public schools but in the new high-immigration scenario become private-school users. ${ }^{66}$

In order to do this let us introduce some simple notation. Consider two time periods: $t=0,1$, respectively, before and after immigration. ${ }^{67}$ Let $E[X \mid$ private, $t]$ be the average characteristics $\mathrm{X}$ of private users in period t. Let also $p_{t}$ denote the share of private users in period $t$. According to our data, $p_{0}=0.26$ and $p_{0}=0.31$, that is, the share of private users was 5 percentage points higher after the immigration wave.

Let us now focus on $E[X \mid$ private, 1$]$, the average characteristics of private users in the high-immigration regime. These users are composed of two groups: those that would have used private schools even prior to immigration, and the switchers. The latter would have stayed in public schools in the absence of immigration but with immigration they switch to private schools. More formally, we have

$$
E[X \mid \text { private }, 1]=E[X \mid \text { private }, 0] \frac{p_{0}}{p_{1}}+E[X \mid \text { private, switch }] \frac{p_{1}-p_{0}}{p_{1}},
$$

where the last term refers to the average characteristics of the private users that switched because of immigration. ${ }^{68}$

\footnotetext{
${ }^{66}$ We thank Chris Taber for this suggestion.

${ }^{67}$ In practice we will take years 2001 and 2008 . We do not use later years to avoid getting into the period of the Great Recession.

${ }^{68}$ This expression requires the identification assumption that immigration only led to switching from public toward private schools. Or, equivalently, that switchers in one direction had the same characteristics as switchers in the other direction.
} 
It is important to note that the data allow for direct measurement of $p_{0}, p_{1}, E[X \mid$ private, 0$]$ and $E[X \mid$ private, 1$]$. Thus we can solve for $E[X \mid$ private, switch $]$, the characteristics of the switchers. Simple manipulation delivers

$$
E[X \mid \text { private, switch }]=E[X \mid \text { private }, 1] \frac{p_{1}}{p_{1}-p_{0}}-E[X \mid \text { private, } 0] \frac{p_{0}}{p_{1}-p_{0}} .
$$

Table 8 reports our findings. Columns 1 and 2 report the characteristics of private users for years 2000 (the beginning of the immigration wave) and 2008 (the end of the immigration wave). ${ }^{69}$ We focus on four characteristics: education of the household head, household income, occupation of the household head, and household size. Not surprisingly, given our analysis so far, the data show that, relative to public-school users, private users in both years had higher education, higher income, were in better occupations and had smaller household size. Notice further that these gaps were larger in year 2000 than in $2008 .^{70}$

We now apply equation (4) to these data. The results are presented in column 4 . We find that, compared to private users at the beginning of the immigration wave $(t=0)$, switchers are less educated, have higher income, and a larger household size, although have slightly better occupations. In short, the switchers are households with weaker socioeconomic background than those households that use private schools regardless of the level of immigration. ${ }^{71}$ In other words, immigration has led to cream-skimming that has mostly affected marginal household in the middle/upper part of the distribution by socio-economic status.

\subsubsection{Effects on quality: student-teacher ratios}

Thus far our findings are largely consistent with the predictions of the political-economy school choice model, although we cannot always rule out alternative explanations. We note that, in the model, the native flight is not driven by xenophobia but a response to a deterioration in the quality of public education. ${ }^{72}$ Consistent with this, Speciale (2012) exploits cross-country variation to show that immigration is associated to reductions in

\footnotetext{
${ }^{69}$ The coefficients reported in the table are the mean gap of each characteristic among private users in each period relative to to public users. These coefficients were obtained from an OLS regression where the outcome variable was the characteristic (e.g. income) and the regressor was an indicator for private user (and an intercept). All regressions used survey weights.

${ }^{70}$ Column 3 is analogous to column 2 but restricting only to households with a native household head. The results are very similar.

${ }^{71}$ Naturally, this is just a rephrasing of our earlier observation that the gaps between private and public users have become narrower over our period of interest.

${ }^{72}$ Importantly, this deterioration is a conscious choice of the decisive voter.
} 
public education expenditures. ${ }^{73}$

The goal of this section is to attempt to evaluate this mechanism on the basis of regional variation. The first issue to address is how to best measure education quality. A convenient, often-used measure is the number of students per teacher. ${ }^{74}$ Unfortunately, we do not have data on student-teacher ratios at the school level but we do know the aggregate student enrollment and the number of teachers at the regional level, separately for private and public schools. Hence, our results on this question are more vulnerable to omitted-variable bias and should be taken as less definitive. ${ }^{75}$

Let us begin by providing some descriptive evidence. Between years 2000 and 2010, student-teacher ratios have fallen importantly in all regions of Spain, both in private and public schools. On average public school student-teacher ratios have decreased by 16 percent over this period, compared to a 20 percent in private schools. There is a great deal of regional heterogeneity, with student-teacher ratios in public schools falling by between 7 and 30 percent between 2000 and 2010 across the 17 Spanish regions. ${ }^{76}$ Let us now examine if this regional variation correlates with the size of the immigration inflows. Figure 7 presents a scatter plot of the 2000-2010 percentage change in the student-teacher ratio in public schools against the change in the region's foreign-born share in the same time period. This figure reveals a strong positive association, indicating that there is indeed a clear positive correlation between immigration and reductions in the measure of the quality of public education. ${ }^{77}$

The hypothesis we want to test is that regions that have experienced an increase in the foreign-born share have suffered an increase in the student-teacher ratios in public schools, suggesting a deterioration of their quality. To that end we propose the following regression model:

\footnotetext{
${ }^{73}$ His interpretation is that immigration increases ethnic diversity and reduces trust and solidarity.

${ }^{74}$ Hanushek (2003) reviews the literature on the effects of class size on student performance. While many studies have used this measure, there is an open debate regarding whether smaller class sizes are cost-effective policy to improve student performance. Krueger (1999) and Angrist and Lavy (1999), among others, find strong support for reducing class sizes. Hoxby (2000) and Anghel and Cabrales (2010) and others find the opposite result. Hence, the issue remains contentious.

${ }^{75}$ For instance, there may be sorting across cities within the region that we are not able to observe. With these caveats in mind we use these regional aggregate data to build the student-teacher ratios.

${ }^{76}$ Ceuta and Melilla, the two Spanish cities in Africa, have been dropped from our sample.

${ }^{77}$ Incidentally, there is also a positive correlation between immigration and changes in student-teacher ratios in private schools. In some regions, such as Catalonia (9) or Murcia (14), student-teacher ratios fell by the same amount in public and private schools. In others, like Madrid (13) or the Canary Islands (5), the reductions were much more pronounced in private schools than in public schools.
} 


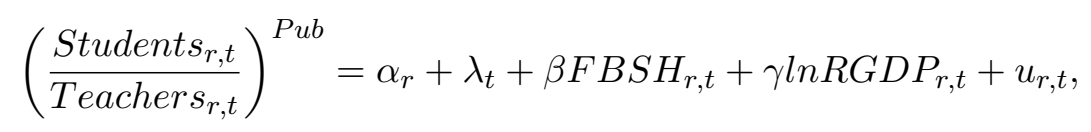

where the dependent variable is the student-teacher ratio in public schools in region $r$ in year $t$, the main regressors of interest are the foreign-born share and the log of real GDP in the region. The latter is meant to proxy for tax revenue, which is an important determinant of the resources (including the number of teachers) that regional governments devote to the funding of public schools. The model also includes a non-parametric time trend in the form of year dummy variables, and region dummy variables. As a sort of placebo test we will also estimate the same model but using the student-teacher ratio in private schools as the dependent variable. In this case we expect to find no effect of immigration.

We now turn to our estimates of the regression model in equation (5). We estimate this model by both OLS and IV since here we are also concerned about a potential endogeneity bias. $^{78}$ Table 9 presents the estimates. In columns 1-4 the dependent variable is the studentteacher ratio in public schools. Column 1 presents OLS estimates based on annual data. The point estimate associated to the foreign-born share is positive and highly significant. We also find a negative association between student-teacher ratios and real GDP, as expected. The latter suggests that when the regional economy is in better shape governments invest more in public schools and hire more teachers. Column 2 presents IV estimates that confirm the OLS results. The IV estimate is higher than OLS, which was to be expected, but standard errors are also higher. Columns 3 and 4 report analogous long-difference estimates that rely only on data for years 2000 and 2010. As a result, the sample size is now 34 (compared to 204 earlier). The point estimates are remarkably similar and we maintain a high level of significance. In conclusion these regression estimates strongly suggest that increases in the regional foreign-born share led to increases in student-teacher ratios in public schools, suggesting a deterioration of quality.

Columns 5-6 conduct a similar analysis but this time the dependent variable is the student-teacher ratio in private schools. Columns 5 and 6 present OLS and IV estimates based on annual data, respectively. Columns 7 and 8 report long-difference estimates. The foreign-born share is now not significantly different from zero, which provides a useful placebo test. Throughout columns 5-8 we find a negative effect of real GDP on studentteacher ratios in private schools and the magnitude appears to be larger than in the case

\footnotetext{
${ }^{78}$ Namely, regions that have experienced a positive economic shock were probably able to invest in their public schools (reducing student-teacher ratios), and simultaneously attracted more immigrants. As a result, OLS estimates might be biased downward. We note though that our specification controls for regional GDP, which should mitigate the size of the bias.
} 
of public schools. This is partly because private-concerted schools receive substantial government funding, and partly because we are not controlling for household income in these aggregate specifications. Hence, an increase in real GDP is proxying for higher household income, which is a strong predictor of households' demand for private schooling.

In conclusion our findings here are consistent with the political-economy mechanism in the school-choice model. The median voter might have decided to reduce the funding and quality of public education in response to immigration. Our findings can also be taken as evidence of congestion effects. Namely, regional governments decide on their total funding for public schools and then teacher-student ratios fluctuate purely as a function of immigration shocks. In this case though it remains to be explained why public school resources were not set in a per-capita basis so as to keep the quality of public education unaffected.

\section{Robustness}

Table 10 provides some sensitivity analysis on the previous results. We focus on three dimensions: long differences, set of instruments, and restricting to the subsample of households headed by a Spanish national.

First, we want to know if the results hold when we adopt a long-differences approach. In this estimation we do not use year-to-year variation but rather 5-year differences based on the observations of years 2001, 2006 and 2011. For these estimates the measurement error in the regional FBSH should be heavily mitigated, which is particularly concerning for periods of net outmigration like the Great Recession. Columns 1-4 report our findings. Column 1 presents OLS estimates of the baseline model. The point estimates for the FBSH and $\log$ of real household income are 6.70 and 0.54 , respectively. These estimates are very similar to those obtained in Table 4 (4.71 and 0.49, respectively). Column 2 adds the vector of variables that capture the origin composition of the immigrant population in each region, as was the case earlier, none of these variables is significantly different from zero. Column 3 presents the 2SLS estimates of the baseline model using long-differences, comparable to the estimates in Table 5. The estimates in that table for tuition expenses ranged between 8.32 and 13.11. The corresponding estimate here is 10.94 , well within the range of estimates obtained using the annual variation. Column 4 allows for heterogeneous responses by educational attainment, which should be compared to the estimates in Table 7 (column 4). There we found no significant effect of immigration on low-education households and a significant point estimate of 11.27 for households headed by someone with at least 
a high-school diploma. Again we now find the same pattern with a point estimate of 8.23 associated to the effects of the FBSH for more educated households. Column 5 reports longdifference estimates for the extensive-margin adjustment, that is, the probability to attend private school. The estimates again confirm the earlier findings: there is only a significant displacement effect for households headed by someone with at least a high-school degree, with similar magnitudes to those reported in Table 7 (column 7).

The second concern is about how would our results be affected if we employed the more commonly used instrumental-variables strategy based on ethnic networks alone. In this vein column 6 reports instrumental-variables estimates when we use only the networks instrument. This column should be compared to column 4 in this same table. We see very similar results, but slightly higher standard errors for the FBSH point estimates. Thus the addition of the gateways instrument appears to increase precision, although by a small amount in this case.

The third concern, addressed in columns 7-10, is that our sample contains both natives and immigrants. Up until 2006 we were not able to distinguish between the two groups in the data so both types of households were included in the sample. Columns 7-8 report estimates for tuition expenditures for the whole sample and for Spanish nationals only for the prerecession years for which we can identify native households, namely, the period 2006-2008. The sample sizes are small (below twenty thousand) compared to the full sample (almost sixty thousand), even though we are not exploiting year-to-year variation, which leads to less precise estimates. However, the point estimates that we find are very similar when we use the full sample or only native households. In both cases the coefficient for the un-interacted FBSH are not significant. The coefficient that interacts the FBSH with the Graduate dummy is positive and of similar magnitude in both columns, but only significant for the subsample of national households. This subsample, despite being smaller (17,755 versus 19,125 households) delivers a more precise estimate of the effect of the FBSH, suggesting that there is a larger response among the national households. In columns 9 and 10 we extend the sample to all years for which we can identify native households (2006-2012). Again the point estimates are similar for all households and for natives only. However, the point estimates for the FBSH terms are less precisely estimated than in the pre-recession subsample, reflecting the increased measurement error in the FBSH during periods of net outmigration. In sum, these estimates suggest that by pooling households headed by Spanish and foreign nationals our estimates suffer of a slight downward bias, making our estimates more conservative. 


\section{Conclusions}

This paper has provided an empirical analysis of school choices in Spain during a period characterized by a large immigration wave and a very severe recession. As expected on the basis of existing literature, we have found that the reductions in household income caused by the recession led to an important reduction in tuition expenditures and thus to a shift from private schools toward tuition-free public schools. In contrast, immigration had the opposite effect. It displaced native households from public toward private schools. Our simulations suggest that the effects of the immigration wave on the school choices of Spanish households were even larger than those of the Great Recession.

More specifically, we have found that immigration led to an increase in educational expenditures, mainly driven by a native flight from tuition-free public schools toward private ones. On the basis of aggregate data on teacher-student ratios we have also found evidence suggesting that immigration lead to a deterioration in the quality of public education. Furthermore we have found evidence of a strong cream-skimming effect, using the language of Altonji et al. (2010). Namely, we have also learned that immigration has had heterogeneous effects on the schooling choices of Spanish households, depending on the socio-economic status of each household. While low-education households have not significantly altered their schooling choices in response to immigration, more educated households have responded vigorously by switching from public schools to private ones. To the extent that tuition may be related to school quality, these findings suggest that immigration has contributed to widening the gap between the educational investments of rich and poorer households. This finding of cream-skimming also points toward greater segregation at the school level, with an increased concentration of low-income native children and immigrant children in public schools, in line with the findings of Cascio and Lewis (2012) for California. This can have important long-term consequences for the educational attainment (Gould et al. (2004, 2009)) and poses an important policy challenge for Spain over the coming decades. Besides threatening social cohesion, immigrant segregation at the school level may hinder economic upward mobility and social integration. Policymakers should develop initiatives

aimed at maintaining the quality of public schools in order to mitigate the flight toward private schools of the children with stronger socio-economic background. 


\section{References}

Altonji, Joseph G. and David Card, "The Effects of Immigration on the Labor Market Outcomes of Less-skilled Natives," in "Immigration, Trade and the Labor Market" NBER Chapters, National Bureau of Economic Research, Inc, December 1991, pp. 201-234.

_, Ching-I Huang, and Christopher R. Taber, "Estimating the Cream Skimming Effect of School Choice," NBER Working Papers 16579, National Bureau of Economic Research, Inc December 2010.

_ , Todd E. Elder, and Christopher R. Taber, "An Evaluation of Instrumental Variable Strategies for Estimating the Effects of Catholic Schooling," Journal of Human Resources, 2005, 40 (4), 791-821.

Amuedo-Dorantes, Catalina and Sara de la Rica, "Labour Market Assimilation of Recent Immigrants in Spain," British Journal of Industrial Relations, 06 2007, 45 (2), 257-284.

_ and _, "Complements or substitutes? Task specialization by gender and nativity in Spain," Labour Economics, October 2011, 18 (5), 697-707.

Anghel, Brindusa and Antonio Cabrales, "The Determinants of Success in Primary Education in Spain," Working Papers 2010-20, FEDEA July 2010.

Angrist, Joshua D. and Victor Lavy, "Using Maimonides' Rule To Estimate The Effect Of Class Size On Scholastic Achievement," The Quarterly Journal of Economics, May 1999, $114(2), 533-575$.

Arellano, Manuel and Gema Zamarro, "The choice between public and private schools with or without subsidies in Spain," Technical Report, CEMFI 2007.

Betts, Julian R. and Robert W. Fairlie, "Does immigration induce 'native flight' from public schools into private schools?," Journal of Public Economics, May 2003, 87 (5-6), 9871012 .

Calero, Jorge and Josep-Oriol Escardibul, "Evaluacion de servicios educativos: el rendimiento en los centros publicos y privados medido en PISA-2003," Hacienda Publica Espanola, 2007, 4, 33-66.

Calsamiglia, Caterina and Maia Guell, "The Illusion of School Choice: Empirical Evidence from Barcelona," Working Papers 712, Federal Reserve Bank of Minneapolis May 2014.

_., Chao Fu, and Maia Guell, "Structural Estimation of a Model of School Choices: the Boston Mechanism vs. Its Alternatives," Working Papers, Mimeo University of Edinburgh 2014.

Card, David, "Immigrant Inflows, Native Outflows, and the Local Labor Market Impacts of Higher Immigration," Journal of Labor Economics, January 2001, 19 (1), 22-64.

Carrasco, Raquel, Juan Jimeno, and A. Ortega, "The effect of immigration on the labor market performance of native-born workers: some evidence for Spain," Journal of Population Economics, July 2008, 21 (3), 627-648.

Cascio, Elizabeth U. and Ethan G. Lewis, "Cracks in the Melting Pot: Immigration, School Choice, and Segregation," American Economic Journal: Economic Policy, August 2012, $4(3), 91-117$.

Chakraborty, Tanika, Olga Nottmeyer, Simone Schller, and Klaus F. Zimmermann, "Beyond the Average: Peer Heterogeneity and Intergenerational Transmission of Education," IZA Discussion Papers 8695, Institute for the Study of Labor (IZA) December 2014. 
Ciccone, Antonio and Walter Garcia-Fontes, "Gender Peer Effects in School, a Birth Cohort Approach," Working paper, Pompeu Fabra and Barcelona GSE May 2014.

Coen-Pirani, Daniele, "Immigration and Spending on Public Education: California, 19702000," Journal of Public Economics, 2011, 95 (11).

de la Rica, Sara, Albrecht Glitz, and Francesc Ortega, "Immigration in Europe: Trends, Policies and Empirical Evidence," Technical Report 7778, IZA Discussion Paper November 2013 .

- and Francesc Ortega, "Economic and Cultural Gaps among Foreign-born Minorities in Spain," IZA Discussion Papers 4115, Institute for the Study of Labor (IZA) April 2009.

del Pozo, D. Trillo, M. Perez Garrido, and J.M. Crespo, "Analisis economico del rendimiento en la prueba de conocimientos y destrezas imprescindibles de la comunidad de Madrid," Technical Report 13, Instituto de Estudios Fiscales 2006.

Dustmann, Christian and Tommaso Frattini, "Immigration: The European Experience," CReAM Discussion Paper Series 1122, Centre for Research and Analysis of Migration (CReAM), Department of Economics, University College London December 2011.

_ , Francesco Fasani, and Biagio Speciale, "Illegal migration and consumption behavior of immigrant households," Mimeo UCL 2015.

-, Tommaso Frattini, and Gianandrea Lanzara, "Educational achievement of second?generation immigrants: an international comparison," Economic Policy, 012012 , $27(69), 143-185$.

Epple, Dennis and Richard E. Romano, "Ends against the middle: Determining public service provision when there are private alternatives," Journal of Public Economics, November 1996, 62 (3), 297-325.

Facchini, Giovanni and Anna Maria Mayda, "Does the Welfare State Affect Individual Attitudes toward Immigrants? Evidence across Countries," The Review of Economics and Statistics, May 2009, 91 (2), 295-314.

Farre, Lidia, Libertad Gonzalez, and Francesc Ortega, "Immigration, Family Responsibilities and the Labor Supply of Skilled Native Women," The B.E. Journal of Economic Analysis $\&$ Policy, June 2011, 11 (1), 1-48.

Fernandez-Huertas, J., A. Ferrer, and A. Saiz, "Immigrant Locations and Native Residential Preferences in Spain: New Ghettos?," Mimeo, MIT Urban Economics Lab 2013.

Fernandez, Raquel and Richard Rogerson, "Income Distribution, Communities, and the Quality of Public Education," The Quarterly Journal of Economics, February 1996, 111 (1), 135-64.

Galor, Oded and Joseph Zeira, "Income Distribution and Macroeconomics," Review of Economic Studies, January 1993, 60 (1), 35-52.

Gerdes, Christer, "Does Immigration Induce 'Native Flight' from Public Schools? Evidence from a Large Scale Voucher Program," IZA Discussion Papers 4788, Institute for the Study of Labor (IZA) February 2010.

Glomm, Gerhard and B Ravikumar, "Public versus Private Investment in Human Capital Endogenous Growth and Income Inequality," Journal of Political Economy, August 1992, 100 (4), 818-34. 
Gonzalez, Libertad, "The Effects of a Universal Child Benefit on Conceptions, Abortions, and Early Maternal Labor Supply," American Economic Journal: Economic Policy, 2013, $5(3)$.

_ and Francesc Ortega, "How Do Very Open Economies Absorb Large Immigration Flows? Evidence from Spanish Regions," Labour Economics, 2011, 18, 57-70.

_ and _ , "Immigration And Housing Booms: Evidence From Spain," Journal of Regional Science, February 2013, 53 (1), 37-59.

Gould, Eric D., Victor Lavy, and M. Daniele Paserman, "Does Immigration Affect the Long-Term Educational Outcomes of Natives? Quasi-Experimental Evidence," Economic Journal, October 2009, 119 (540), 1243-1269.

Gould, Eric, Victor Lavy, and Daniele M. Paserman, "Immigrating to Opportunity: Estimating The Effect of School Quality Using a Natural Experiment On Ethiopians in Israel," The Quarterly Journal of Economics, May 2004, 119 (2), 489-526.

Hanushek, Eric A., "The Failure of Input-Based Schooling Policies," Economic Journal, February 2003, 113 (485), F64-F98.

Hoxby, Caroline M., "The Effects Of Class Size On Student Achievement: New Evidence From Population Variation," The Quarterly Journal of Economics, November 2000, 115 (4), 1239-1285.

Hunt, Jennifer, "The Impact of Immigration on the Educational Attainment of Natives," NBER Working Papers 18047, National Bureau of Economic Research, Inc May 2012.

Kristen, Cornelia, "Primary School Choice and Ethnic School Segregation in German Elementary Schools," European Sociological Review, 2008, 24 (4), 495-510.

Krueger, Alan B., "Experimental Estimates Of Education Production Functions," The Quarterly Journal of Economics, May 1999, 114 (2), 497-532.

Llera, Roberto Fernandez and Manuel Muniz Perez, "Colegios concertados y selecin de escuela en Espaa: un crculo vicioso," Presupuesto y Gasto Pblico, 2012, 18, 97-118.

Llull, Joan, "Immigration, Wages and Education: A Labor Market Equilibrium Structural Model," Barcelona GSE Working paper, 2013.

OCU, "The growing school expenses (in Spanish)," Technical Report 373, Organizacion de Consumidores y Usuarios September 2012.

Razin, Assaf, Efraim Sadka, and Phillip Swagel, "Tax burden and migration: a political economy theory and evidence," Journal of Public Economics, August 2002, 85 (2), 167190.

Saiz, Albert and Susan Wachter, "Immigration and the Neighborhood," American Economic Journal: Economic Policy, May 2011, 3 (2), 169-88.

Schneeweis, Nicole, "Immigrant Concentration in Schools: Consequences for Native and Migrant Students," IZA Discussion Papers 7230, Institute for the Study of Labor (IZA) February 2013.

Speciale, Biagio, "Does immigration affect public education expenditures? Quasiexperimental evidence," Journal of Public Economics, 2012, 96 (910), 773 - 783.

Tanaka, Ryuichi, Lidia Farre, and Francesc Ortega, "Immigration, Naturalization, and the Future of Public Education," IZA Discussion Papers 8342, Institute for the Study of Labor (IZA) July 2014. 
Zimmermann, Klaus F., ed., European Migration: What Do We Know? number 9780199257355. In 'OUP Catalogue.', Oxford University Press, March 2005.

Zimmermann, Laura, Liliya Gataullina, Amelie Constant, and Klaus F. Zimmermann, "Human capital and ethnic self-identification of immigrants," Economics Letters, March 2008, $98(3), 235-239$. 
Table 1: Summary statistics 2000-2012 (all years pooled, unweighted)

\begin{tabular}{lccccc}
\hline \hline \multicolumn{1}{c}{ Variable } & Mean & Std. Dev. & Min. & Max. & N \\
\hline Year & 2007.3 & 3.5 & 2000 & 2012 & 59,809 \\
Region (CCAA) & 8.8 & 4.9 & 1 & 17 & 59,809 \\
N. children 3-17 & 1.48 & 0.64 & 1 & 7 & 59,809 \\
HS grad. & 0.28 & 0.45 & 0 & 1 & 59,809 \\
College grad. & 0.21 & 0.41 & 0 & 1 & 59,809 \\
& & & & & \\
FBSH & 0.11 & 0.06 & 0.01 & 0.24 & 59,809 \\
FB Europe / FB & 0.41 & 0.10 & 0.23 & 0.68 & 59,809 \\
FB Africa / FB & 0.17 & 0.07 & 0.03 & 0.40 & 59,809 \\
FB America / FB & 0.38 & 0.11 & 0.12 & 0.58 & 59,809 \\
FB Asia / FB & 0.04 & 0.022 & 0.01 & 0.11 & 59,809 \\
& & & & & \\
Hh. income & 25115.4 & 14863.7 & 0 & 386364 & 59,809 \\
Real hh. income & 27263.8 & 15613 & 0.98 & 404071.4 & 59,809 \\
Ln RGDP & 13.28 & 0.89 & 11.10 & 14.58 & 59,809 \\
Tuition per child & 245.3 & 751.7 & 1 & 24006.6 & 59,809 \\
Real tuition per child & 264.5 & 802.7 & 0.9 & 26113.4 & 59,809 \\
Real tuition conditional on private & 865.1 & 1264.9 & 30 & 26113.4 & 18,193 \\
Share private (30 euros) & 0.33 & 0.47 & 0 & 1 & 59,809 \\
Share private (100 euros) & 0.24 & 0.43 & 0 & 1 & 59,809 \\
\hline \hline
\end{tabular}


Table 2: Population-weighted means (selected years)

\begin{tabular}{lcccc}
\hline \hline Variable & 2000 & 2004 & 2008 & 2012 \\
\hline N. children 3-17 & 1.51 & 1.49 & 1.44 & 1.45 \\
Share HS grad. & 0.18 & 0.20 & 0.30 & 0.32 \\
Share College grad. & 0.18 & 0.23 & 0.20 & 0.22 \\
& & & & \\
FBSH & 0.04 & 0.09 & 0.13 & 0.14 \\
FB Europe / FB & 0.47 & 0.37 & 0.42 & 0.42 \\
FB Africa / FB & 0.21 & 0.18 & 0.16 & 0.16 \\
FB America / FB & 0.27 & 0.41 & 0.38 & 0.36 \\
FB Asia / FB & 0.04 & 0.04 & 0.04 & 0.05 \\
& & & & \\
Real hh. income & 23,621 & 25,777 & 28,590 & 24,437 \\
Real tuition per child & 229 & 269 & 331 & 333 \\
Private (30 euros) & 0.28 & 0.28 & 0.31 & 0.32 \\
Private (100 euros) & 0.24 & 0.24 & 0.25 & 0.26 \\
Real tuition cond. private & 866 & 958 & 1,049 & 1,037 \\
Ln RGDP & 13.44 & 13.64 & 13.75 & 13.65 \\
\hline \hline
\end{tabular}




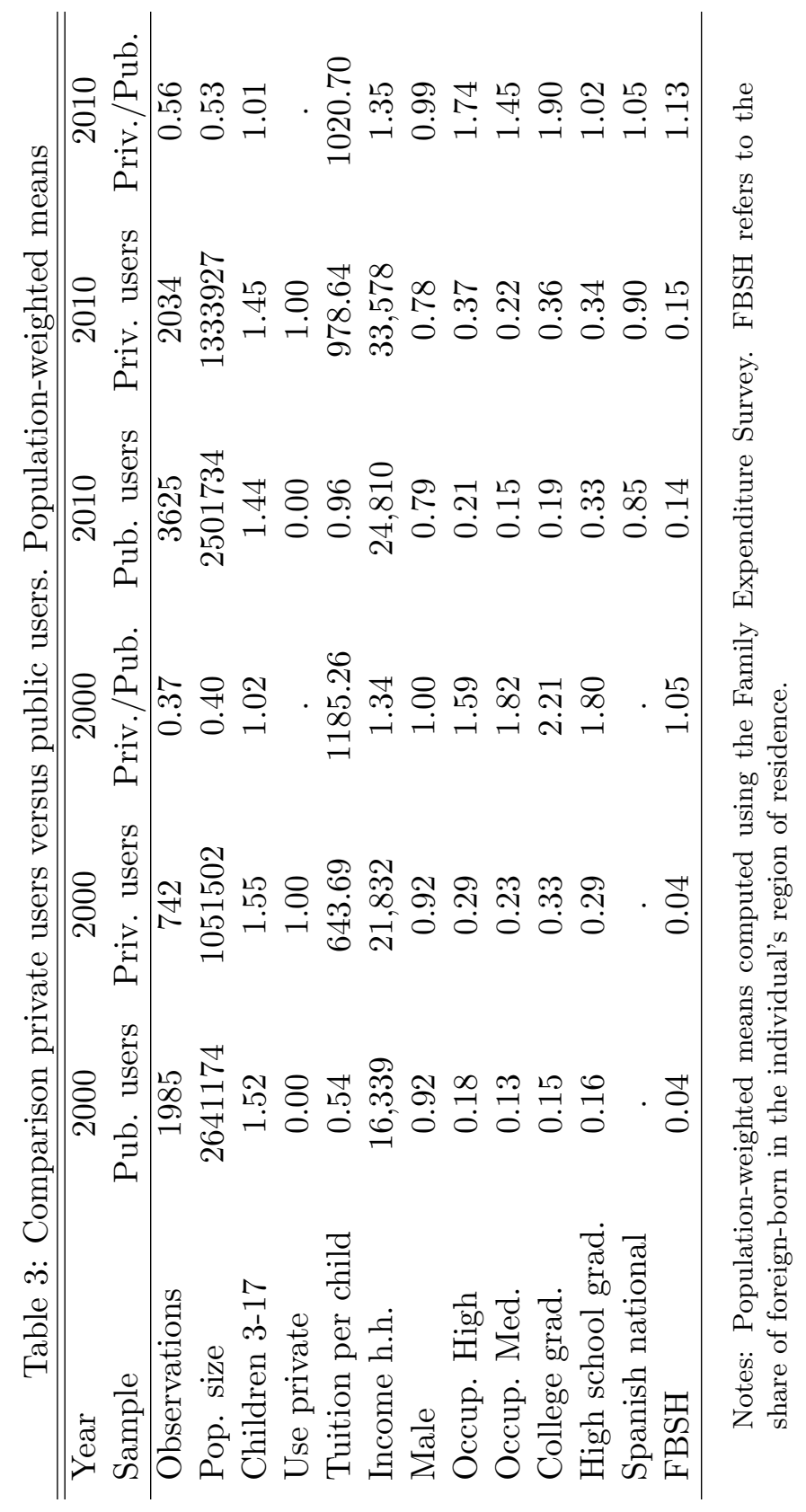




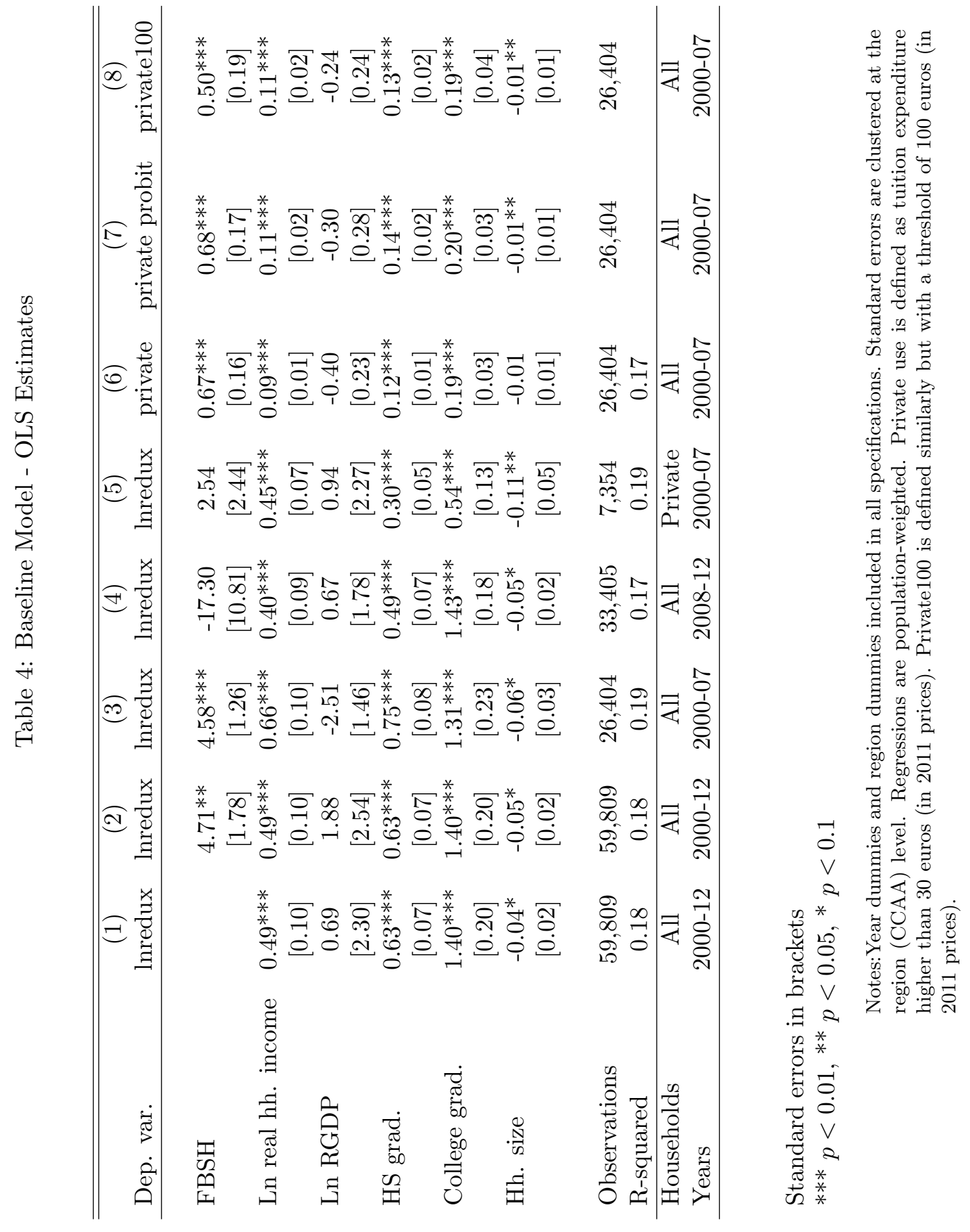




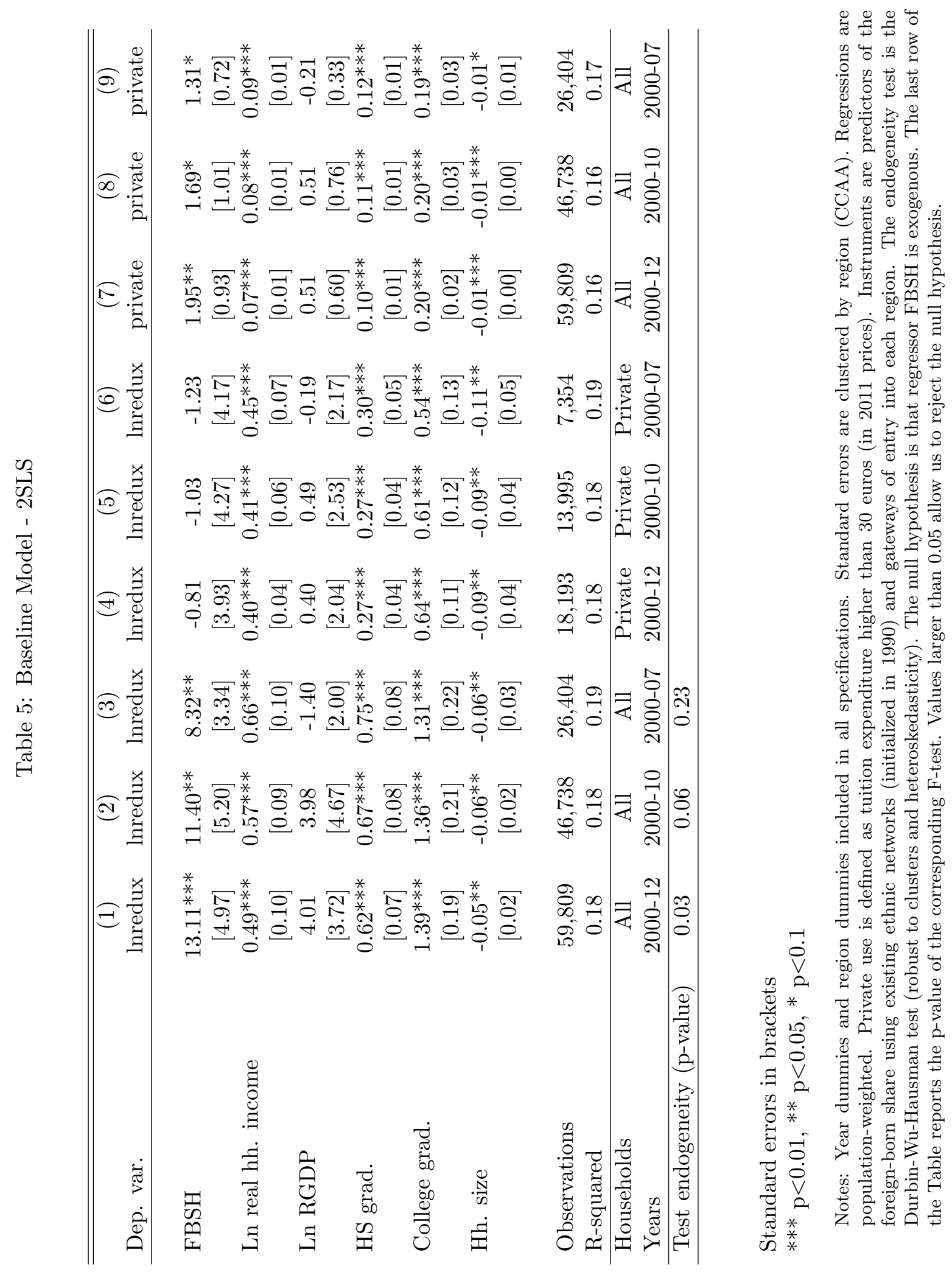


Table 6: Heterogeneous Effects by Immigrant Origin

\begin{tabular}{|c|c|c|c|c|c|}
\hline & $\begin{array}{c}(1) \\
\text { lnredux }\end{array}$ & $\begin{array}{c}(2) \\
\text { lnredux }\end{array}$ & $\begin{array}{c}(3) \\
\text { lnredux }\end{array}$ & $\begin{array}{c}(4) \\
\text { private }\end{array}$ & $\begin{array}{c}(5) \\
\text { lnredux }\end{array}$ \\
\hline FBSH & $\begin{array}{c}4.58^{* * *} \\
{[1.26]}\end{array}$ & & $\begin{array}{c}4.93^{* * *} \\
{[1.65]}\end{array}$ & $\begin{array}{c}0.73^{* *} \\
{[0.27]}\end{array}$ & $\begin{array}{c}2.98 \\
{[2.25]}\end{array}$ \\
\hline FB Europe / Pop. & & $\begin{array}{l}2.17 \\
{[2.07]}\end{array}$ & & & \\
\hline FB Africa / Pop. & & $\begin{array}{c}5.77 \\
{[7.69]}\end{array}$ & & & \\
\hline FB America / Pop. & & $\begin{array}{c}9.44^{* * *} \\
{[2.73]}\end{array}$ & & & \\
\hline FB Asia / Pop. & & $\begin{array}{l}-24.10 \\
{[20.90]}\end{array}$ & & & \\
\hline FB Africa / FB & & & $\begin{array}{c}0.79 \\
{[1.20]}\end{array}$ & $\begin{array}{c}0.14 \\
{[0.20]}\end{array}$ & $\begin{array}{c}0.62 \\
{[1.47]}\end{array}$ \\
\hline FB America / FB & & & $\begin{array}{c}0.80 \\
{[0.66]}\end{array}$ & $\begin{array}{l}0.23^{*} \\
{[0.13]}\end{array}$ & $\begin{array}{l}-0.63 \\
{[0.54]}\end{array}$ \\
\hline FB Asia / FB & & & $\begin{array}{l}-2.93 \\
{[2.44]}\end{array}$ & $\begin{array}{c}-0.66^{*} \\
{[0.38]}\end{array}$ & $\begin{array}{l}-0.21 \\
{[3.47]}\end{array}$ \\
\hline Ln Real GDP & $\begin{array}{l}-2.51 \\
{[1.46]}\end{array}$ & $\begin{array}{l}-3.30 \\
{[2.00]}\end{array}$ & $\begin{array}{r}-3.32^{*} \\
{[1.63]}\end{array}$ & $\begin{array}{c}-0.60^{* *} \\
{[0.28]}\end{array}$ & $\begin{array}{c}0.83 \\
{[2.84]}\end{array}$ \\
\hline Ln real hh. income & $\begin{array}{c}0.66^{* * *} \\
{[0.10]}\end{array}$ & $\begin{array}{c}0.66^{* * *} \\
{[0.10]}\end{array}$ & $\begin{array}{c}0.66^{* * *} \\
{[0.10]}\end{array}$ & $\begin{array}{c}0.09^{* * *} \\
{[0.01]}\end{array}$ & $\begin{array}{c}0.45^{* * *} \\
{[0.07]}\end{array}$ \\
\hline HS grad. & $\begin{array}{c}0.75^{* * *} \\
{[0.08]}\end{array}$ & $\begin{array}{c}0.75^{* * *} \\
{[0.08]}\end{array}$ & $\begin{array}{c}0.75^{* * *} \\
{[0.08]}\end{array}$ & $\begin{array}{c}0.12^{* * *} \\
{[0.01]}\end{array}$ & $\begin{array}{c}0.30^{* * *} \\
{[0.05]}\end{array}$ \\
\hline College grad. & $\begin{array}{c}1.31^{* * *} \\
{[0.23]}\end{array}$ & $\begin{array}{c}1.31^{* * *} \\
{[0.23]}\end{array}$ & $\begin{array}{c}1.31^{* * *} \\
{[0.23]}\end{array}$ & $\begin{array}{c}0.19^{* * *} \\
{[0.03]}\end{array}$ & $\begin{array}{c}0.54^{* * *} \\
{[0.13]}\end{array}$ \\
\hline Hh. size & $\begin{array}{c}-0.06^{*} \\
{[0.03]}\end{array}$ & $\begin{array}{c}-0.06^{*} \\
{[0.03]}\end{array}$ & $\begin{array}{c}-0.06^{*} \\
{[0.03]}\end{array}$ & $\begin{array}{l}-0.01 \\
{[0.01]}\end{array}$ & $\begin{array}{c}-0.11^{* *} \\
{[0.05]}\end{array}$ \\
\hline Observations & 26,404 & 26,404 & 26,404 & 26,404 & 7,354 \\
\hline R-squared & 0.19 & 0.19 & 0.19 & 0.17 & 0.19 \\
\hline Years & $2000-2007$ & $2000-2007$ & $2000-2007$ & $2000-2007$ & $2000-2007$ \\
\hline
\end{tabular}

Notes:Year dummies and region dummies included in all specifications. Regressions are population-weighted.

Private use is defined as tuition expenditure higher than 30 euros (in 2011 prices). 


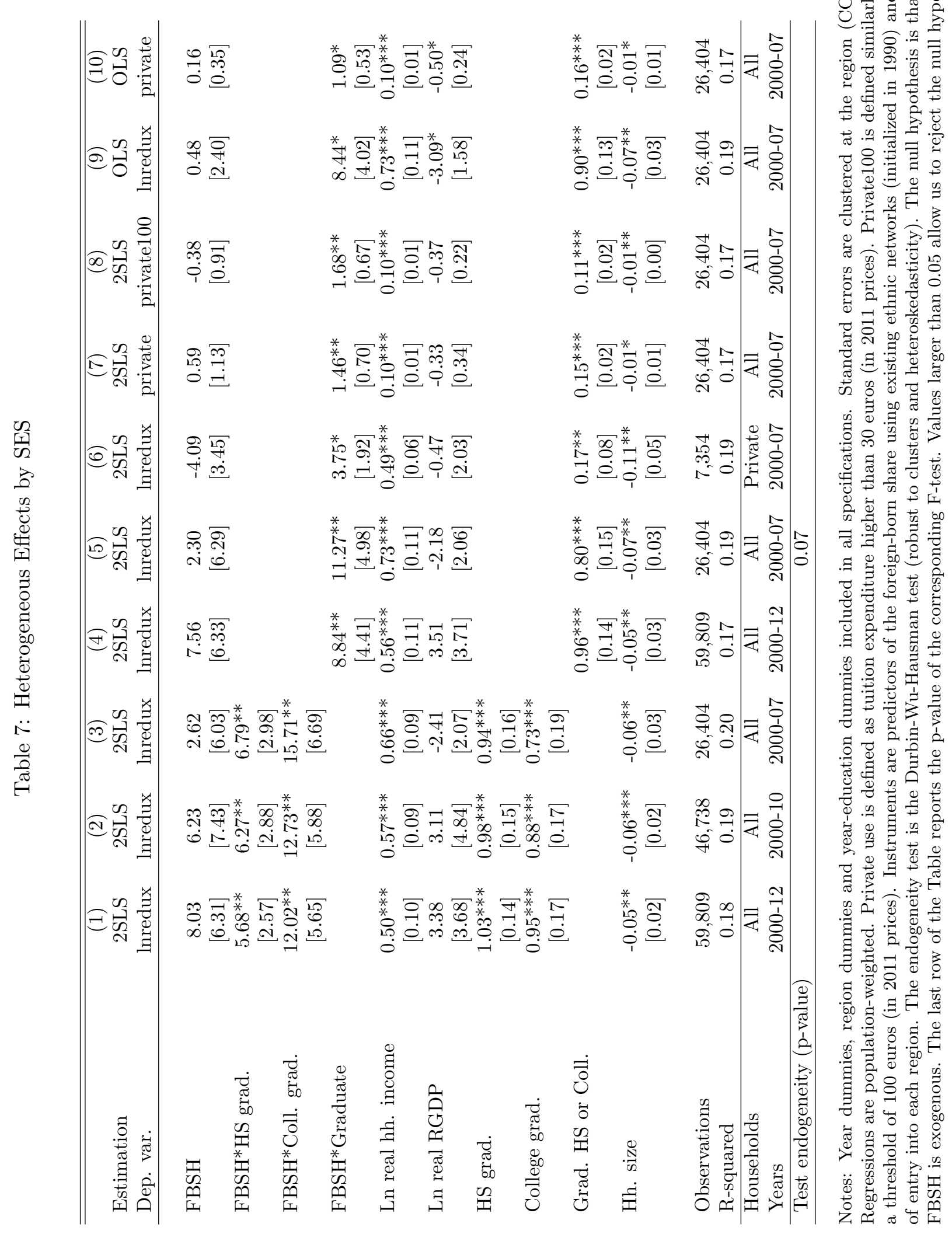


Table 8: Characteristics of Switchers

\begin{tabular}{lccccc}
\hline \hline & 1 & 2 & 3 & 4 & 5 \\
\hline Year & 2000 & 2008 & 2008 & $\cdot$ & $\cdot$ \\
Sample & All Private & All Private & Natives Private & All Switchers Private & Native Switchers \\
\hline College grad. & 0.2 & 0.18 & 0.18 & 0.08 & 0.18 \\
Real hh. income & 5.74 & 5.42 & 4.82 & 3.76 & 2.59 \\
Occup. High & 0.16 & 0.17 & 0.16 & 0.22 & 0.12 \\
Household size & -0.12 & -0.07 & -0.04 & 0.19 & 0.07 \\
\hline Prob. Private & 0.26 & 0.31 & 0.33 &. & $\cdot$ \\
\hline \hline
\end{tabular}

Notes: The coefficients reported in this table are the mean gap of each characteristic among private users in each period relative to to public users. Household income is in thousands of constant-price euros. These coefficients were obtained from an OLS regression where the outcome variable was the characteristic (e.g. income) and the regressor was an indicator for private user (and an intercept). All regressions used survey weights. All coefficients reported were statistically significant at a $5 \%$ level. 


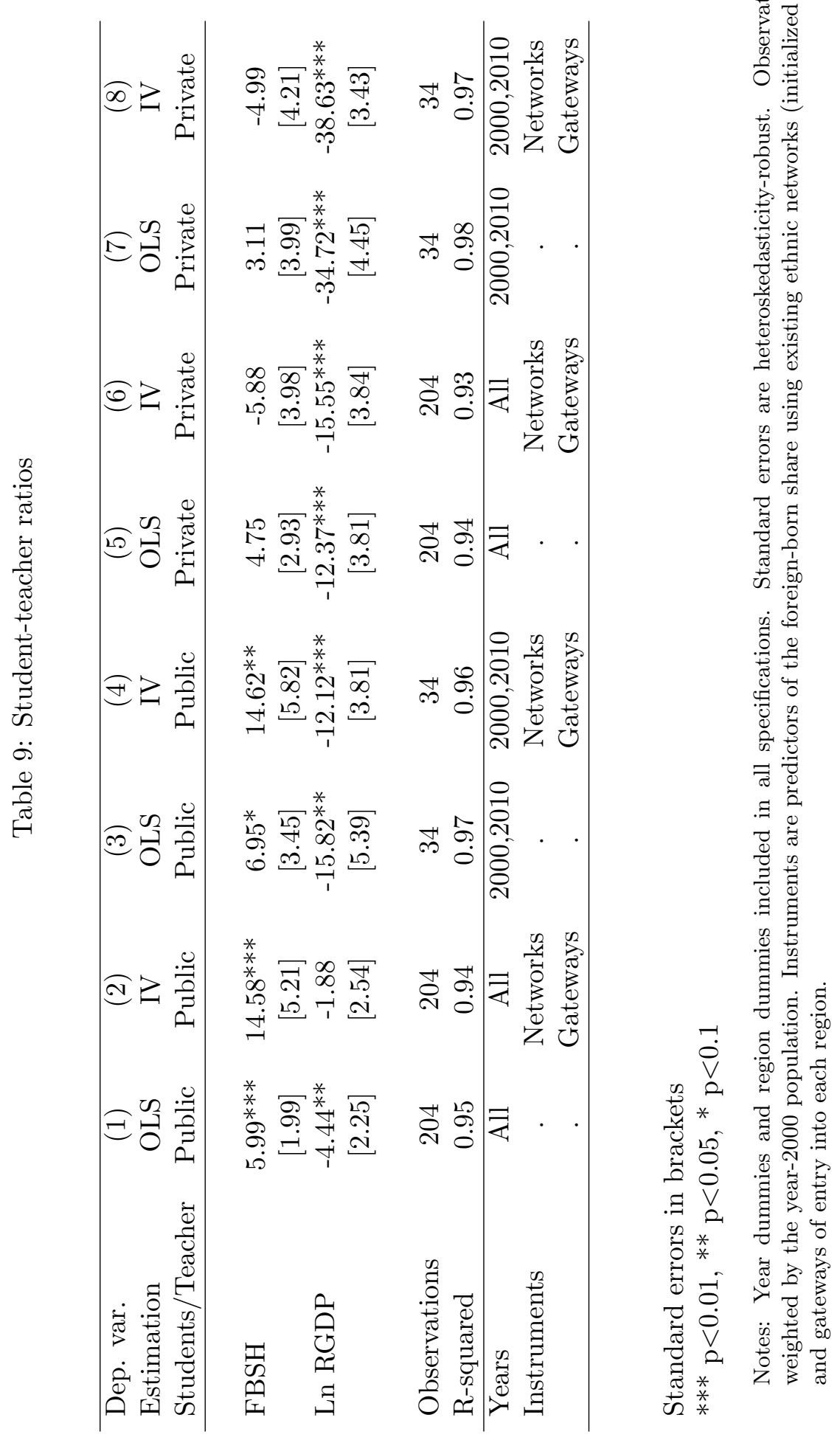




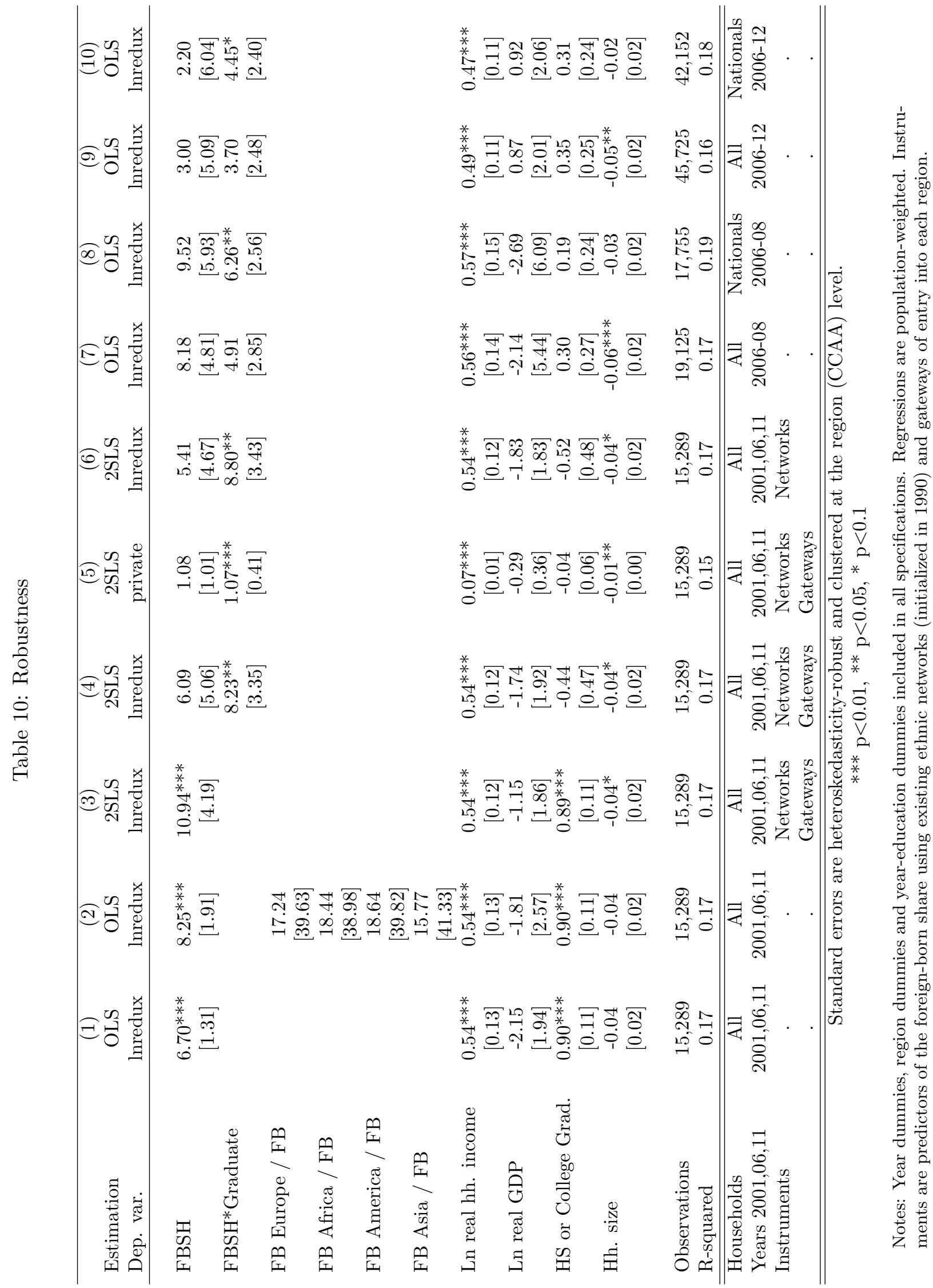


Figure 1: Foreign-born Share

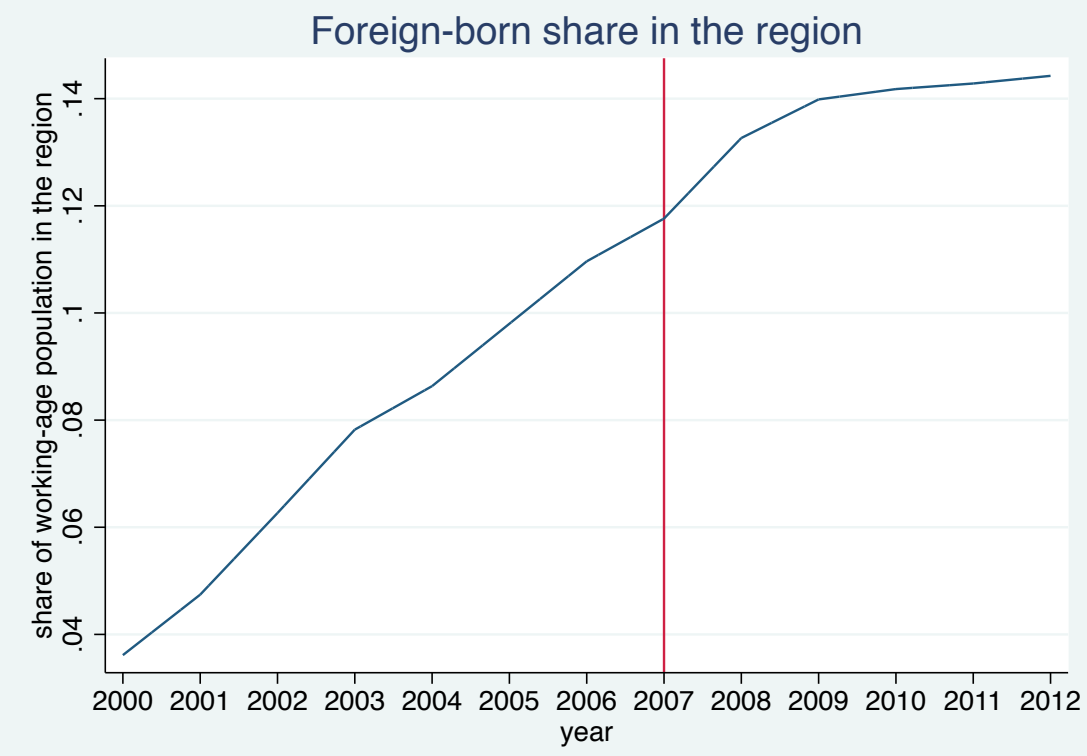

Notes: Registry data.

Figure 2: The Boom and Recession

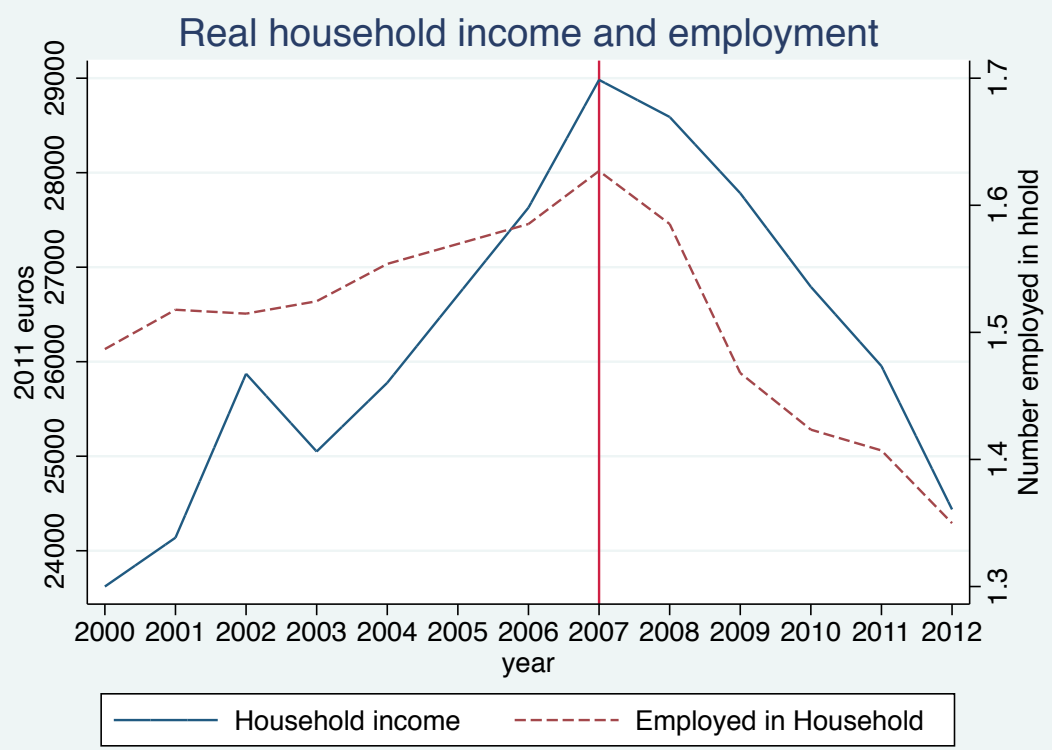

Notes: Family Expenditure Survey. 
Figure 3: Growth Student Population, 2001-2010

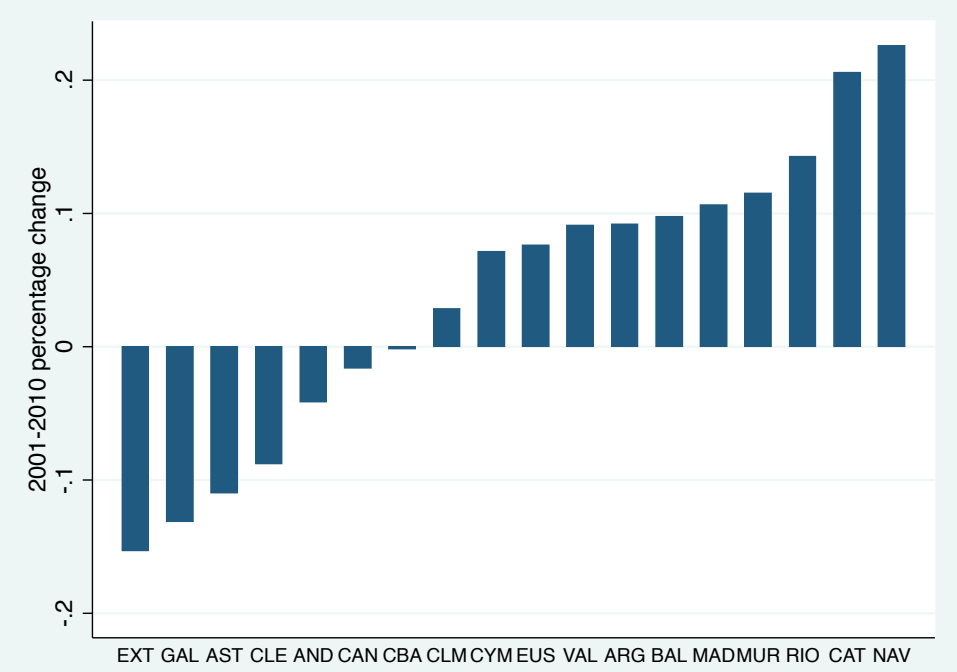

Notes: The data correspond to academic years 2001-2002 and 2010-2011. We report the percentage change in the student population (elementary plus compulsory secondary schooling) combining public and private schools. Each bar corresponds to one autonomous community (sorted in increasing order): Extremadura, Galicia, Asturias, Castilla y Leon, Andalucia, Canarias, Cantabria, Castilla La Mancha, Ceuta and Melilla, Euskadi, Comunitat Valenciana, Aragon, Balearic Islands, Madrid, Murcia, Rioja, Catalunya, and Navarra.

Figure 4: Number of Households

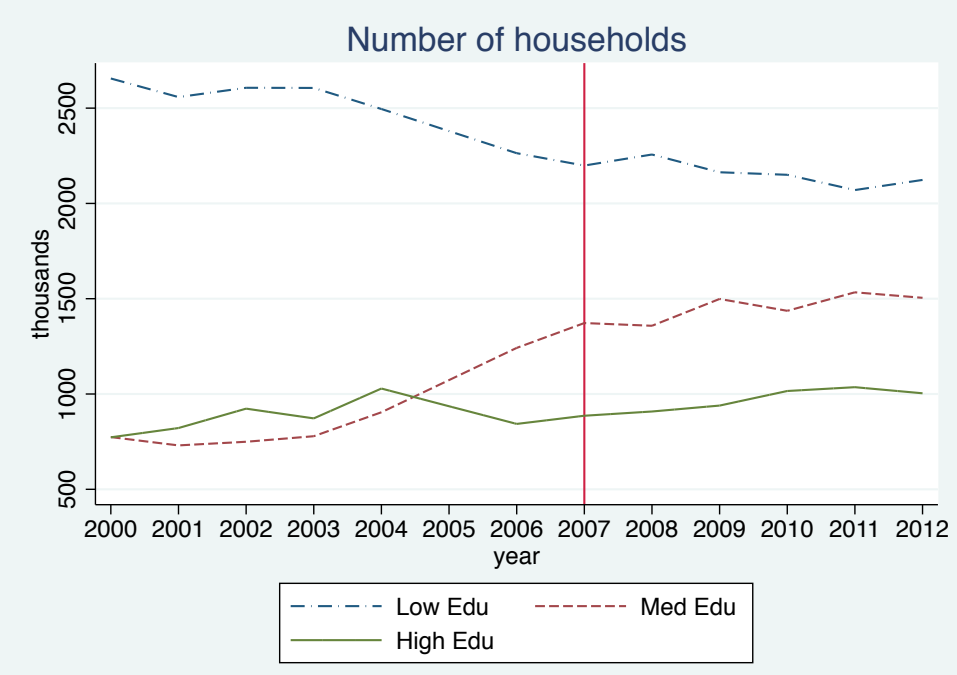

Notes: Estimated on the basis of the Spanish Labor Force Survey, using the appropriate population weights. Low, medium and high education households are, respectively, those headed by a high-school dropout, a high-school graduate and a college graduate. 
Figure 5: Trends in tuition spending by education group

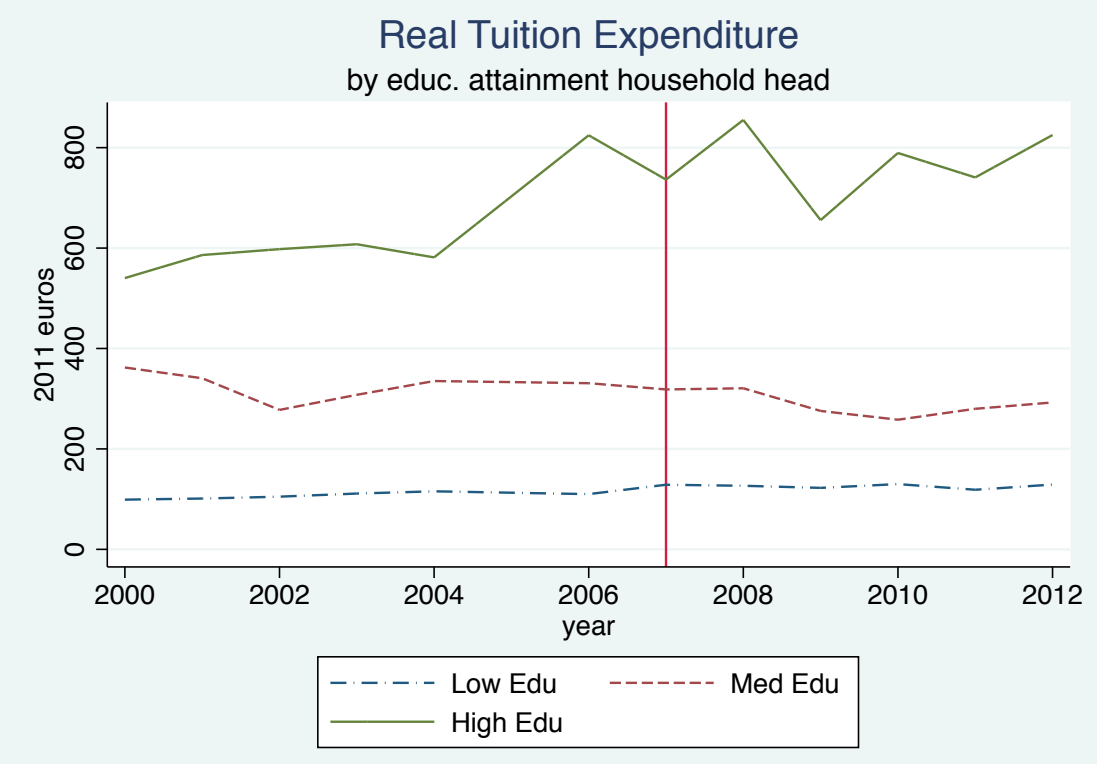

Notes: Family Expenditure Survey.

Figure 6: Trends in share attending private school by education group

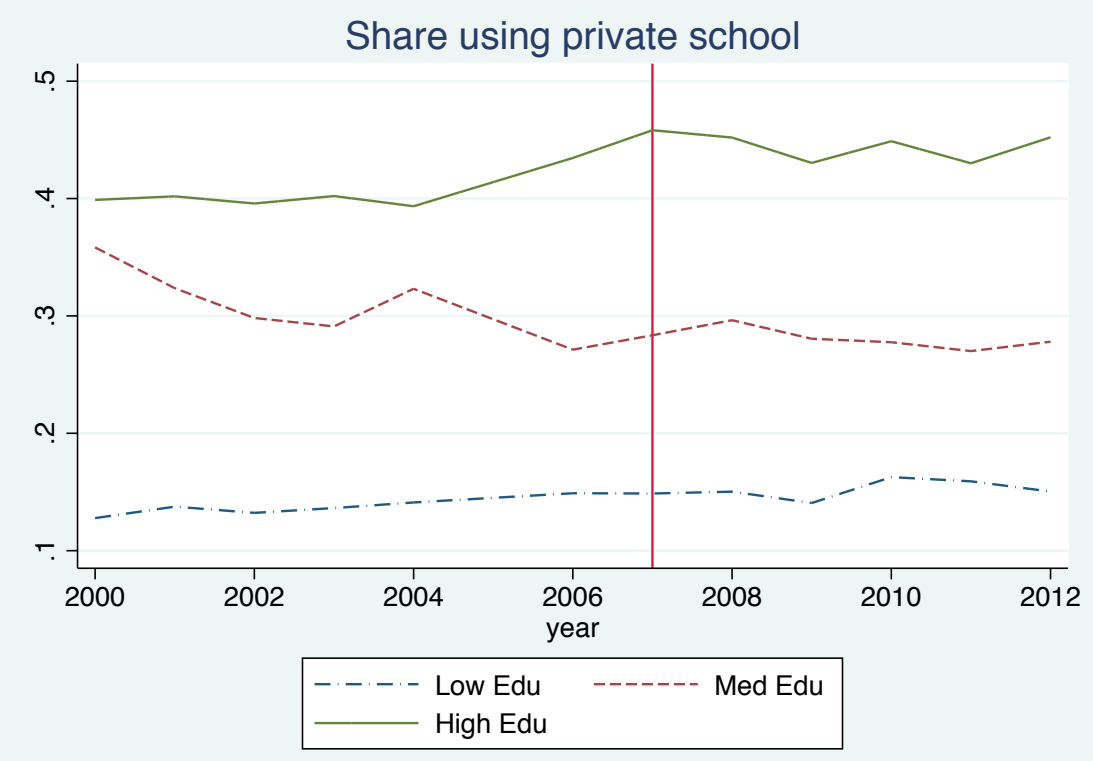

Notes: Family Expenditure Survey. 
Figure 7: Percentage change in the student-teacher ratio between 2000 and 2010 against the change in the foreign-born share in the region)

Pch. student-teacher ratio in public schools

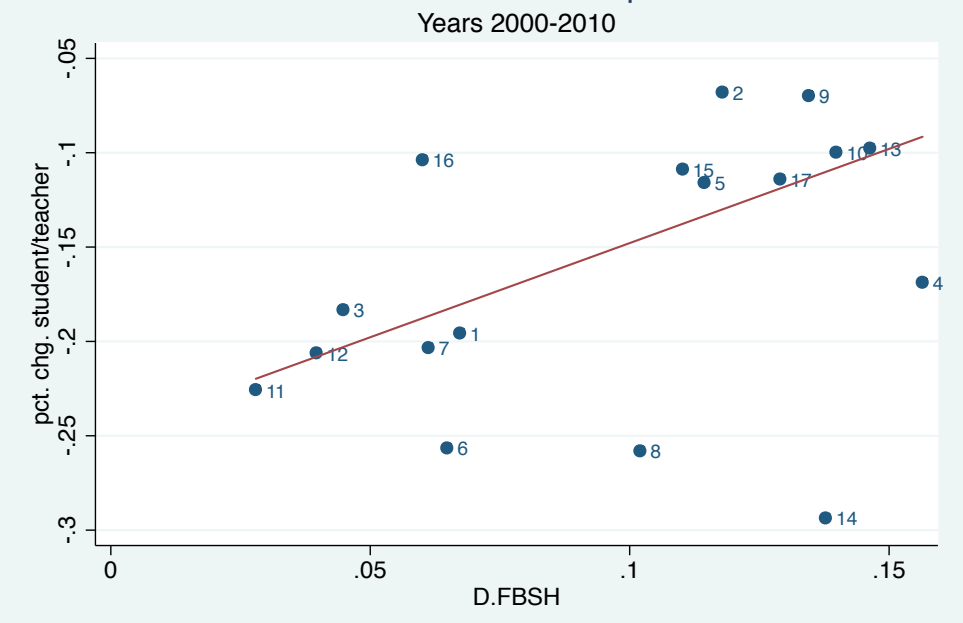

Notes: In linear regression fit each region is weighted by its year-2000 population. Next we list all regions (autonomous communities) and their numerical code: Andalucia (1), Aragon (2), Asturias (3), Balearic Islands (4), Canary Islands (5), Cantabria (6), Castilla Leon (7), Castilla La Mancha (8), Catalonia (9), Valencia (10), Extremadura (11), Galicia (12), Madrid (13), Murcia (14), Navarra (15), Basque Country (16), La Rioja (17). 
Figure 8: The Effects of the Great Recession: Total Effect

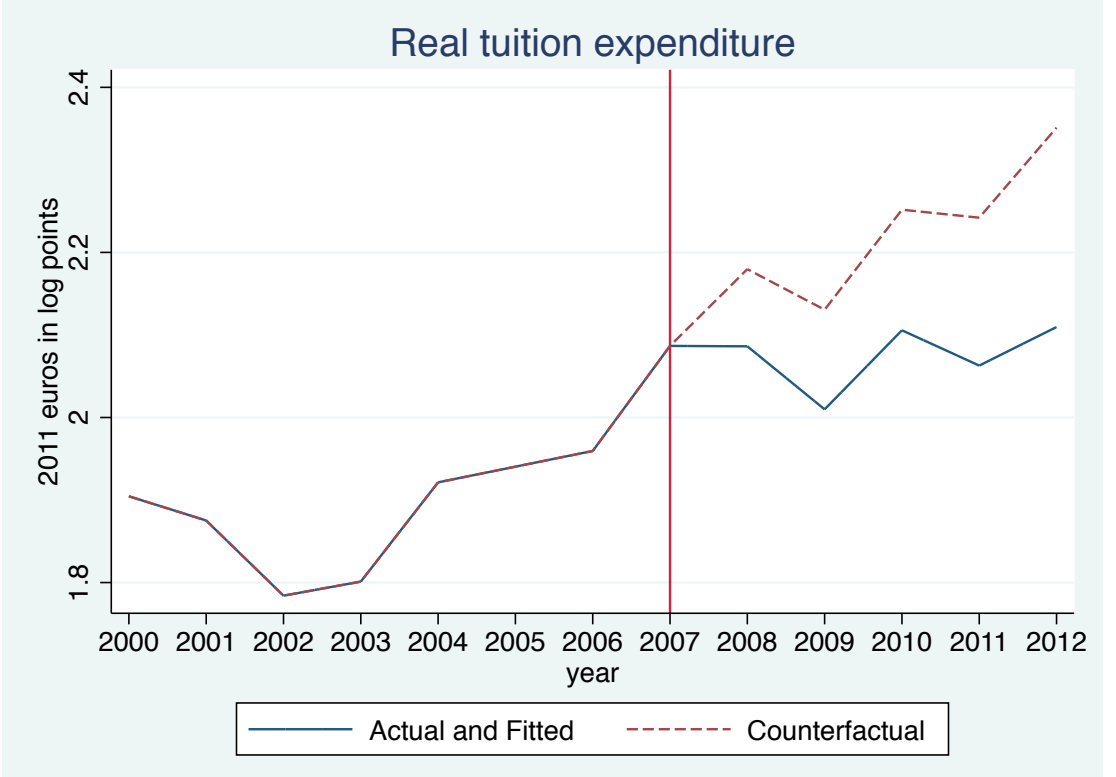

Notes: In the counterfactual we assign to each household the constant 2007 average household income in its region-education cell for years 2008-2011.

Figure 9: The Effects of the Great Recession: Extensive Margin

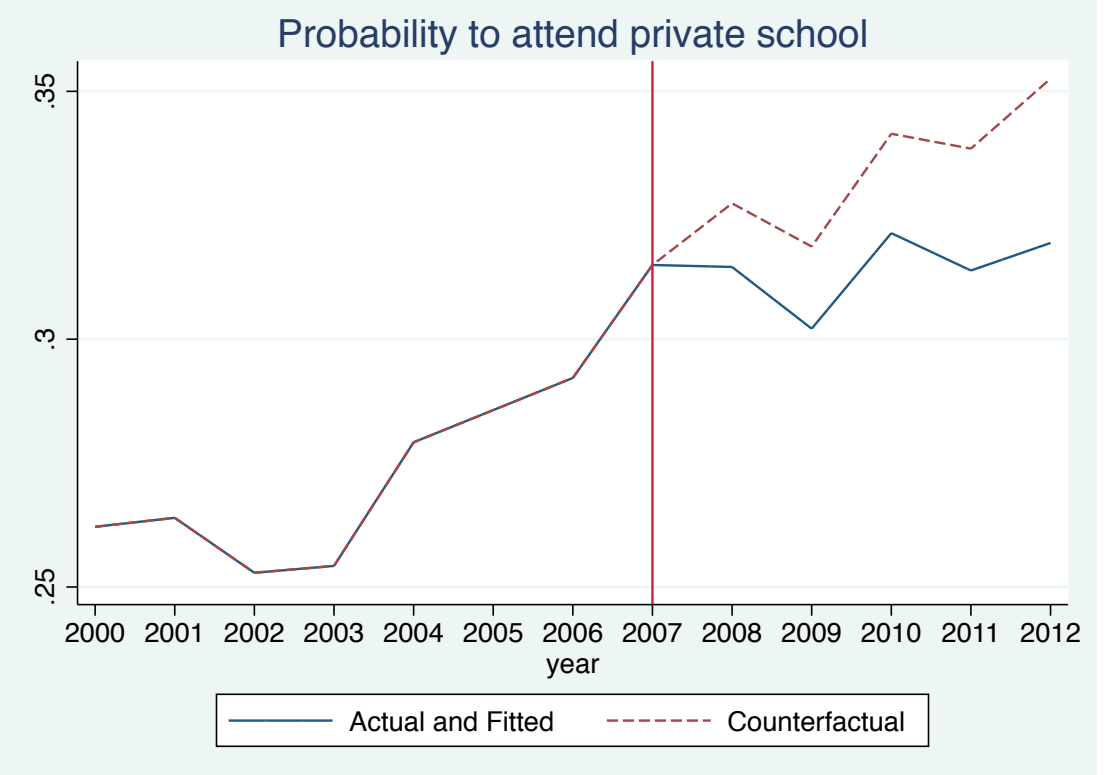

Notes: In the counterfactual we assign to each household the constant 2007 average household income in its region-education cell for years 2008-2011. Private school attendance defined using the 100-euro threshold. 
Figure 10: The Effects of the Immigration Wave: Total Effect

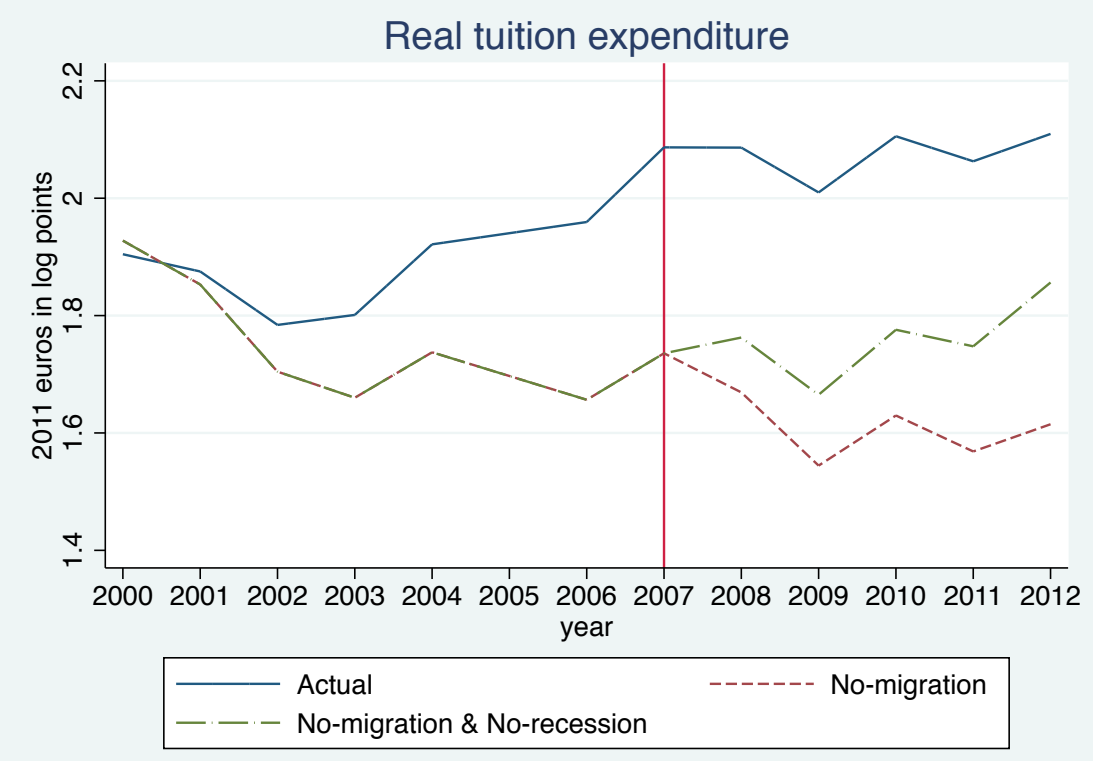

Notes: In the counterfactual we assign to each region the constant 2000 regional foreign-born share for years 2001-2011.

Figure 11: The Effects of the Immigration Wave: Extensive Margin

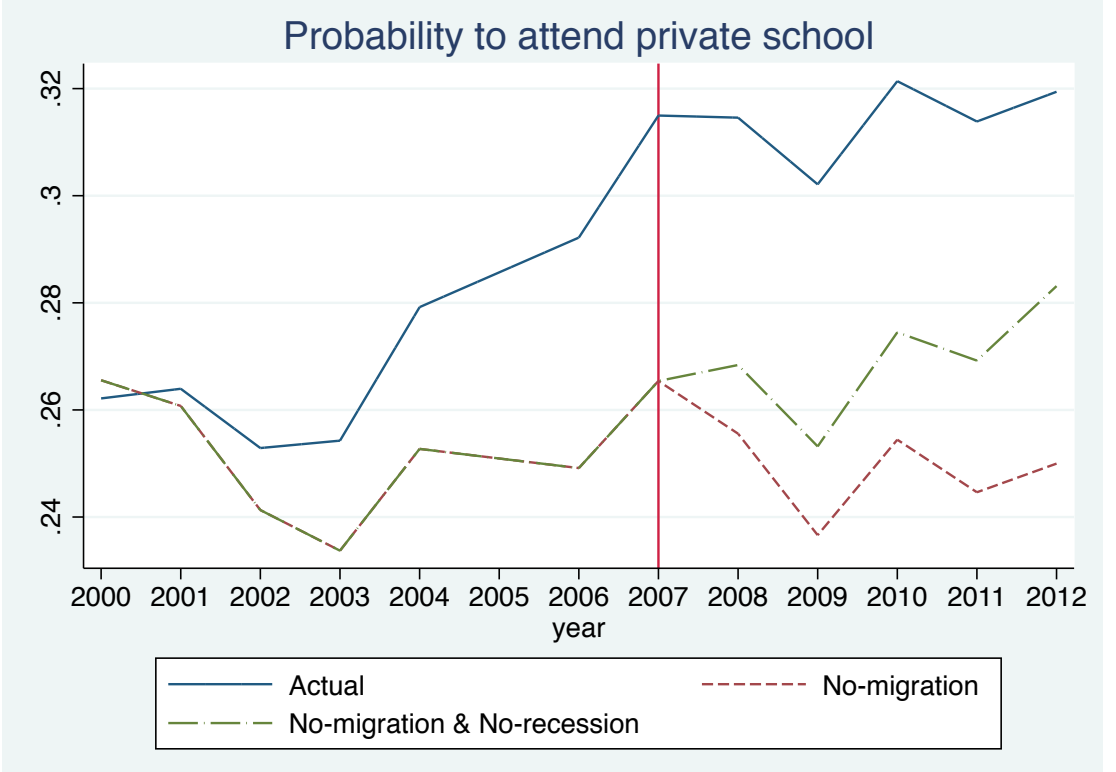

Notes: In the counterfactual we assign to each region the constant 2000 regional foreign-born share for years 2001-2011. 


\section{Appendices}

\section{A Instrument definitions}

The instrumental-variables strategy applied here is based on Gonzalez and Ortega (2013). We simply extended their variables to cover our sample period. We provide a succinct description of the instruments here. We refer the reader to the original source for further details.

\section{A.1 Ethnic networks Instrument}

This instrument was first introduced in Card (2001), building on a more primitive earlier version by Altonji and Card (1991) and has been used extensively in the immigration literature. In essence, it is a predictor for actual population growth (immigrant inflows) into a province, using historical information on immigrant networks defined by country of origin. We expect current location decisions of migrants to be influenced by the location decisions of earlier migrants from the same country of origin.

Specifically, we define the following predictor of the current stock of foreign-born population in province $\mathrm{i}$ and year $\mathrm{t}$ :

$$
\left.Z N_{r, t}=\sum_{c}\left(\frac{F B_{c, r, t_{0}}}{F B_{c}, t_{0}}\right) F B\right) c, t,
$$

for year $t<t_{0}$, where $F B_{c, r, t_{0}}$ is the number of individuals born in foreign country $\mathrm{c}$ that inhabited province $\mathrm{i}$ in some base year $t_{0}$. Thus, the term in parenthesis is the share of c-born individuals that lived in each province in the base year, which provides a measure of the size of that source country network in each province. The only time-varying term in the equation is $F B_{c, t}$, the stock of individuals originated from country c that live in Spain in year t. Hence, an inflow of, say, Polish immigrants into Spain in 2006 will lead to a predicted contemporaneous increase in the Polish population in each province in proportion to the size of the Polish enclave in that province in the base year.

\section{A.2 Gateways Instrument}

Let us now turn to the gateways instrument. The main idea is to exploit the differences in physical accessibility across Spanish provinces. Immigrants enter Spain either by land, sea, or air, and the most common mode of transportation varies widely by country of origin. We consider three main dimensions of accessibility: the existence and size of airports and ports in the province, as measured by passenger traffic in a pre-sample year, and distance to France (and hence the rest of Europe) along the major highways. Given these infrastructures, when there is a surge in immigration from, say, Morocco (presumably driven by economic conditions at origin), those provinces that are more accessible from Morocco will be expected to receive larger inflows. In this example provinces with ports in along the Mediterranean coast will be particularly attractive. In part the motivation behind this instrument is similar to Hunt (1992), who uses distance from Algeria to French provinces (plus other variables) as an instrument for the location choices of the 1962 Algerian repatriates (pieds-noirs).

More specifically, the construction of the gateways instrument involves three steps. First, let us define ar, $\mathrm{m}$ as the accessibility of province $\mathrm{r}$ through transportation mode $\mathrm{m}$, where $\mathrm{m}$ = air, sea, land, and the sum across all provinces equals one (for each $\mathrm{m}$ ). The accessibility terms by air and sea are giving by the share of all arrivals into Spain that entered through province $r$ by plane or boat, in year 1999. For the land transportation mode ar,land is defined as the distance from province rs capital city to the city of Girona (close to the French border and right by the main highway connecting Spain and France), normalized in a way that the sum (across provinces) of all these terms adds up to one. Second, we obtain 
information on how important each model of transportation is for each country of origin. More specifically, for each mode of transportation $\mathrm{m}$ and country of origin $\mathrm{c}$, we define preference of origin country c for transportation mode $\mathrm{m}$ (denoted by bm,c) as the share of all individuals born in country c that entered Spain using transportation mode $\mathrm{m}$ in a given year. By construction, these terms also add up to one (across modes of transportation, for any given origin country c). Third, we now multiply the previous two terms to obtain a province-source country specific term indicating the degree of accessibility by each mode of transportation of each Spanish province from the point of view of each country of origin. By adding up across modes of transportation we obtain the overall degree of accessibility of each Spanish province from each country of origin. That is,

$$
\gamma_{r, c}=a_{r}^{\text {land }} b_{c}^{\text {land }}+a_{r}^{\text {sea }} b_{c}^{\text {sea }}+a_{r}^{\text {air }} b_{c}^{\text {air }} .
$$

The final step is analogous to the construction of the ethnic networks. We use the matrix of $\gamma_{r, c}$ terms to build a predictor of the current stock of foreign-born population in province $\mathrm{i}$ and year $\mathrm{t}$ :

$$
Z G_{r, t}=\sum_{c} \gamma_{r, c} F B_{c, t}
$$

for $t<t_{0}$. Within-province changes over time in ZG are the basis for our gateways instrument. Consider some economic, social or political event in, say, Ecuador, that triggers a wave of migration out of the country. ${ }^{79}$ Our predictor will suggest that if many Ecuadorians choose Spain as their destination, those provinces constituting the main gateways for Ecuadorians (mainly, those with an important international airport) will receive a large inflow of Ecuadorians, for reasons uncorrelated with local economic conditions. ${ }^{80}$

\section{B Weak identification analysis}

Table B.1 reports the first-stage regressions for our main model. The three endogenous regressors are FBSH, FBSH interacted with an indicator for medium education, and FBSH interacted with an indicator for high education. The vector of excluded instruments contains six variables: the predictor for the FBSH based on ethnic networks, the predictor for the FBSH based on gateways, and each of these interacted with the medium education indicator and the high education indicator. We focus on the subsample for years 2000-2007, preceding the Great Recession. Thus the corresponding two-stage least-squares estimates can be found in column 3 of Table 7.

The F-statistics of the excluded instruments are 5.55, 18.87 and 23.48, for FBSH, FBSH*edumed, and FBSH*eduhigh, respectively. On the basis of the rule of thumb, these statistics suggest that there may be a problem of weak identification for FBSH. More formally, we test the null hypothesis of joint weak identification. The Kleibergen-Paap F statistic is 6.51, which is above of the two less demanding critical values reported by Stock and Yogo but below the two more demanding ones. ${ }^{81}$

Intuitively, the relatively weak joint identification seems to arise from the coefficient of the FBSH. To formalize this intuition we conduct Angrist-Pischke F tests of individual

\footnotetext{
${ }^{79}$ Bertoli et al (2011) studies in detail the reasons for the surge, and sharp posterior decline, in Ecuadorian migration to Spain.

${ }^{80} \mathrm{As}$ a check, we note that the average across years and provinces for the gateways instrument has to be roughly similar with the average for the networks instrument. After all, both instruments are weighted sums of the Spain-wide stocks of foreign-born by year and region of origin. The Appendix contains the data sources used in the construction of the gateways instrument.

${ }^{81}$ For the case of 3 endogenous regressors and 6 excluded instruments the critical values for the weak identification test range from 4.40 to 12.20 for maximal IV relative bias ranging from $5 \%$ to $30 \%$. Strictly speaking, these critical values are only appropriate under i.i.d. errors.
} 
weak identification, which take into account the presence of multiple endogenous regressors. The AP F statistics for the three endogenous regressors (FBSH, FBSH*edumed, and FBSH*eduhigh) are 8.01, 17.11 and 19.87. It is common to compare these statistics to the Stock and Yogo weak identification critical values for a single endogenous regressor. These values range from 5.34 to 19.28 for maximal IV relative bias of $30 \%$ to $5 \%$. Thus for the coefficient of FBSH we can only reject the null of individually weak identification for a $20 \%$ maximal relative bias. For FBSH*edumed we can reject the null for a $10 \%$ maximal relative bias. And for $\mathrm{FBSH}^{*}$ edumed we can reject even the most stringent critical value (5\% maximal relative bias). In conclusion, we are fairly confident about the identification of the effect of the FBSH on medium and highly educated households but much less so for low educated households.

As a further check we also test for the joint significance of the endogenous regressors in the main equation using the Anderson-Rubin F-test, which is robust to weak instruments.. The critical value is 35.97 with an associated p-value of less than 0.0001 . Hence, we are fairly confident of a non-zero joint effect for the coefficients of interest. 
Table B.1: First-stage regressions

\begin{tabular}{lcc}
\hline \hline & $(1)$ & $(2)$ \\
Dep. var. & FBSH & FBSH*Graduate (HS or Coll.) \\
\hline \multirow{2}{*}{ ivznet } & 0.29 & $-0.09^{* * *}$ \\
& {$[0.20]$} & {$[0.02]$} \\
ivznet*Graduate (HS or Coll.) & 0.01 & $0.55^{* * *}$ \\
& {$[0.01]$} & {$[0.16]$} \\
ivzgate & 0.00 & $-0.01^{*}$ \\
& {$[0.05]$} & {$[0.01]$} \\
ivzgate*Graduate (HS or Coll.) & -0.00 & 0.03 \\
& {$[0.00]$} & {$[0.03]$} \\
Ln RGDP & -0.18 & -0.08 \\
& {$[0.21]$} & {$[0.10]$} \\
Graduate (HS or Coll.) & -0.00 & $0.01^{* *}$ \\
& {$[0.00]$} & {$[0.01]$} \\
Ln real Hh. inc. & -0.00 & $-0.00^{* *}$ \\
Hh. size & {$[0.00]$} & {$[0.00]$} \\
& $0.00^{*}$ & $0.00^{* *}$ \\
Observations & {$[0.00]$} & {$[0.00]$} \\
R-squared & & \\
\hline F test excluded inst. & 26,404 & 26,404 \\
AP F test & 0.94 & 0.94 \\
& 6.36 & 15.43 \\
& 8.43 & 18.66 \\
& $* 0.01$, & \\
& &
\end{tabular}

Notes: Year dummies and region dummies included in all specifications. We are not showing the coefficients for the exogenous regressors. The sample used here is 2000-2007. Standard errors are heteroskedasticityrobust and clustered by region (17 units). Observations are weighted by the year-2000 population. Instruments are predictors of the foreign-born share using existing ethnic networks (initialized in 1990) and gateways of entry into each region. AP is the Angrist-Pischke F test of individual weak identification of each of the endogenous regressors. 